\title{
Depolarization ratio profiling at several wavelengths in pure Saharan dust during SAMUM 2006
}

\author{
By VOLKER FREUDENTHALER ${ }^{1 *}$, MICHAEL ESSELBORN ${ }^{2}$, MATTHIAS WIEGNER ${ }^{1}$, \\ BIRGIT HEESE ${ }^{3}$, MATTHIAS TESCHE ${ }^{3}$, ALBERT ANSMANN ${ }^{3}$, DETLEF MÜLLER ${ }^{3}$, \\ DIETRICH ALTHAUSEN ${ }^{3}$, MARTIN WIRTH $^{2}$, ANDREAS FIX ${ }^{2}$, GERHARD EHRET $^{2}$, \\ PETER KNIPPERTZ ${ }^{4}$, CARLOS TOLEDANO ${ }^{1}$, JOSEF GASTEIGER ${ }^{1}$, \\ MARKUS GARHAMMER ${ }^{1}$ and MEINHARD SEEFELDNER ${ }^{1},{ }^{1}$ Meteorological Institute, \\ Ludwig-Maximilians-Universität, Theresienstr. 37, 80333 Munich, Germany; ${ }^{2}$ Institute of Atmospheric Physics, \\ German Aerospace Center (DLR), Oberpfaffenhofen, 82234 Wessling, Germany; ${ }^{3}$ Leibniz Institute for Tropospheric \\ Research, Permoserstr. 15, 04318 Leipzig, Germany; ${ }^{4}$ Institute for Atmospheric Physics, Johannes Gutenberg \\ University, Becherweg 21, 55099 Mainz, Germany
}

(Manuscript received 2 January 2008; in final form 18 August 2008)

\begin{abstract}
Vertical profiles of the linear particle depolarization ratio of pure dust clouds were measured during the Saharan Mineral Dust Experiment (SAMUM) at Ouarzazate, Morocco $\left(30.9^{\circ} \mathrm{N},-6.9^{\circ} \mathrm{E}\right)$, close to source regions in May-June 2006, with four lidar systems at four wavelengths $(355,532,710$ and $1064 \mathrm{~nm})$. The intercomparison of the lidar systems is accompanied by a discussion of the different calibration methods, including a new, advanced method, and a detailed error analysis. Over the whole SAMUM periode pure dust layers show a mean linear particle depolarization ratio at $532 \mathrm{~nm}$ of 0.31, in the range between 0.27 and 0.35, with a mean Ångström exponent (AE, 440-870 nm) of 0.18 (range 0.04-0.34) and still high mean linear particle depolarization ratio between 0.21 and 0.25 during periods with aerosol optical thickness less than 0.1, with a mean AE of 0.76 (range 0.65-1.00), which represents a negative correlation of the linear particle depolarization ratio with the $\mathrm{AE}$. A slight decrease of the linear particle depolarization ratio with wavelength was found between 532 and $1064 \mathrm{~nm}$ from $0.31 \pm 0.03$ to $0.27 \pm 0.04$.
\end{abstract}

\section{Introduction}

Shape, size distribution and composition of aerosol particles influence their scattering characteristics and thus the radiative impact. The polarization lidar technique (Schotland et al., 1971; Sassen, 1991; Sassen, 2005) is a well-established method to distinguish ice clouds from water clouds and to identify layers with ice crystals in mixed-phase clouds (e.g. Ansmann et al., 2005, 2007). Freudenthaler et al. (1996) applied a scanning polarization lidar to study the evolution of contrails. The technique has been used to identify the type of polar stratospheric clouds (Reichardt et al., 2000; Toon et al., 2000; Sassen, 2005) and volcanic ash in the troposphere and stratosphere (Hayashida et al., 1984; Winker and Osborn, 1992; Sassen et al., 2007). The polarization lidar is also well suited for aerosol profiling (McNeil and Carswell, 1975; Murayama et al., 1996; Gobbi,

\footnotetext{
* Corresponding author.

e-mail: volker.freudenthaler@meteo.physik.uni-muenchen.de DOI: $10.1111 /$ j.1600-0889.2008.00396.x
}

1998; Cairo et al., 1999; Sassen et al., 2007) and allows us to unambiguously discriminate desert dust from other aerosols (Gobbi et al., 2000; di Sarra et al., 2001; Sakai et al., 2002; Müller et al., 2003; Iwasaka et al., 2003; Murayama et al., 2004). Based on model calculations, it has been demonstrated that the spectral dependence of the dust linear depolarization ratio is sensitive to the size distribution of the nonspherical scatterers (Mishchenko and Sassen, 1998). Thus, observations of the linear depolarization ratio at several wavelengths may be used in retrieval schemes (Dubovik et al., 2006) to improve the estimation of the microphysical properties of dust from optical measurements (D. Müller, personal communication, 2008; Wiegner et al., 2008). First dual-wavelength aerosol polarization lidar measurements were presented by Sugimoto et al. (2002).

The linear depolarization ratio $\delta$ is defined as the ratio of the cross-polarized lidar return signal to the parallel-polarized backscatter signal. The planes of polarization of the employed two detectors are parallel and orthogonal to the plane of polarization of the transmitted linearly polarized laser. The method is discussed in detail in Section 2. Although the polarization lidar 
technique appears to be rather simple, and thus robust and reliable, several sources for systematic errors can have a significant impact on the result and can introduce large errors. These error sources are discussed in Section 3. On the other hand, rather accurate values of the depolarization ratio of desert dust (including the spectral slope of the ratio) are required for further use in the above mentioned retrieval schemes. An extensive error analysis is thus as important as the measurement itself. Several papers (Biele et al., 2000; Reichardt et al., 2003; Alvarez et al., 2006) show how highly accurate depolarization observations can be realized. In this paper, a further technique is discussed, which improves the calibration of the depolarization channels.

We begin with the presentation of the polarization lidar technique (methodology, lidar setup) in Sections 2 and 3. In Section 4 , the observations are discussed. For the first time, dust depolarization ratios at four wavelengths were measured. The unique field site was close to the source of the dust particles so that the depolarization properties of pure dust could be investigated. Section 5 summarizes the main findings, and the error analysis is treated in the Appendix.

\section{Polarization lidar method}

Measurements of the linear depolarization ratio $\delta$ with lidars are often performed with the aim to just discern between the dry, the liquid and the ice phase of aerosols and clouds in the profiles of one lidar system, which requires only a relative measure of $\delta$ with a low accuracy of the absolute values. During Saharan Mineral Dust Experiment (SAMUM), it was attempted to measure a possible wavelength dependence of the dust particle linear depolarization ratio $\delta^{\mathrm{p}}$, with four different lidar systems at four wavelengths as inputs for model calculations of $\delta^{\mathrm{p}}$ regarding the particles shapes and size distribution. Thus, the uncertainty of the absolute values must be known and should be small compared with the expected natural variance. The total backscattered power $P(r)$ with their dependence on the distance $r$ from the lidar is described by the lidar equation

$P=\frac{\eta \beta(r) \tau^{2}(r)}{r^{2}}$

where $\eta$ is the system constant, $\beta$ the backscatter coefficient, and the factor $\tau^{2}$ accounts for the atmospheric transmittance on the way from the lidar to the scattering volume, and back. For the determination of $\delta$ the lidars used in this study measure the atmospheric backscatter signals in two receiver channels, parallel- and cross-polarized with respect to the plane of the linear polarized output of the laser beam. The two polarization components are separated in the receiver by means of polarizing beamsplitter cubes (PBC). But this separation is not perfect. Furthermore the polarizing beamsplitter might be misaligned with respect to the plane of polarization of the emitted laser beam, and additionally, a rotation of the polarization plane is used for the relative calibration of the two receiver channels. Therefore,

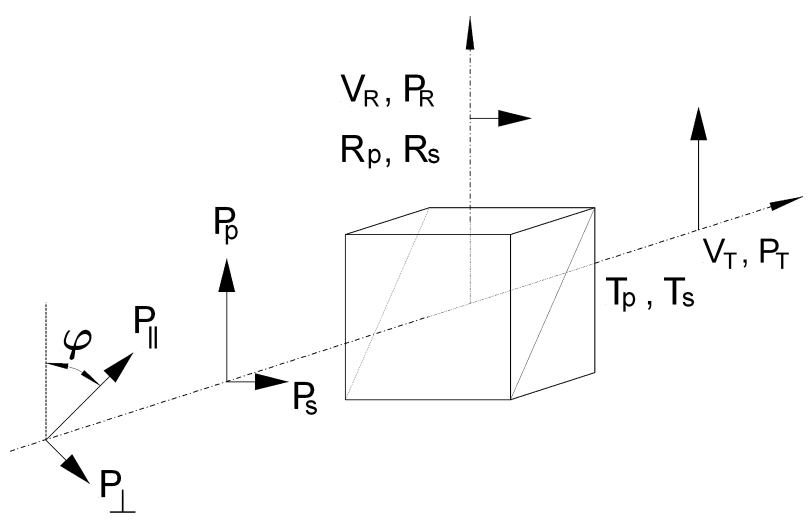

Fig. 1. Signal power components in a receiver of a depolarization lidar with a polarizing beamsplitter cube with reflectivities $R_{\mathrm{p}}$ and $R_{\mathrm{S}}$ and transmittances $T_{\mathrm{p}}$ and $T_{\mathrm{s}}$ for linearly polarized light parallel (p) and perpendicular (s) to the incident plane of the polarizing beamsplitter. $P_{\mathrm{R}}$ and $P_{\mathrm{T}}$ are the measured quantities in the reflected and transmitted path, respectively, and $V_{\mathrm{R}}$ and $V_{\mathrm{T}}$ are the corresponding amplification factors including the optical transmittances.

we show the necessary equations of the angle $\varphi$ between the plane of polarization of the laser and the incident plane of the polarizing beamsplitter cube, according to Fig. 1.

The backscatter powers before the PBC are (skipping the range dependence in the following for convenience)

$P_{\perp}=\frac{\eta_{\perp}\left(\beta_{\perp}^{\mathrm{p}}+\beta_{\perp}^{\mathrm{m}}\right) \tau^{2}}{r^{2}}$,

$P_{\|}=\frac{\eta_{\|}\left(\beta_{\|}^{\mathrm{p}}+\beta_{\|}^{\mathrm{m}}\right) \tau^{2}}{r^{2}}$,

with the system constants $\eta_{\|}$and $\eta_{\perp}$ including here only the laser power and the telescope aperture, assuming negligible diattenuation of the optics before the $\mathrm{PBC}$, for example, a telescope or dichroic beamsplitters. The backscatter coefficient $\beta$ is split up in the parallel- $\left(\beta_{\|}\right)$and cross-polarized $\left(\beta_{\perp}\right)$ components of the backscatter from particles $\left(\beta^{\mathrm{p}}\right)$ and from molecules $\left(\beta^{\mathrm{m}}\right)$. The total backscatter power $P$ and the total backscatter coefficient $\beta$ are the sum of both polarized components:

$P=P_{\|}+P_{\perp}$

The ratio of the total backscatter coefficient to the molecular component is called the backscatter ratio $\mathbf{R}$

$\mathbf{R}=\frac{\beta^{m}+\beta^{p}}{\beta^{m}}$

and the ratio of the total cross- to the total parallel-polarized backscatter coefficient is called the linear volume depolarization ratio $\delta^{\mathrm{v}}$ :

$\delta^{\mathrm{v}}=\frac{\beta_{\perp}}{\beta_{\|}}=\frac{P_{\perp}}{P_{\|}}$. 
The power components with respect to the incident plane of the $\mathrm{PBC}$ are

$$
\begin{aligned}
& P_{\mathrm{s}}(\varphi)=P_{\|} \sin ^{2}(\varphi)+P_{\perp} \cos ^{2}(\varphi), \\
& P_{\mathrm{p}}(\varphi)=P_{\|} \cos ^{2}(\varphi)+P_{\perp} \sin ^{2}(\varphi) .
\end{aligned}
$$

The subscripts $\mathrm{p}$ and $\mathrm{s}$ denote the planes parallel and perpendicular to the incident plane of the PBC (see Fig. 1), respectively, and $\varphi$ is the angle between the plane of polarization of the laser and the incident plane of the PBC. Depending on this angle, the cross polarized signal $P_{\perp}$ can be measured in the reflected (for $\left.\varphi=0^{\circ}\right)$ or in the transmitted path $\left(\varphi=90^{\circ}\right)$. Hence, we denote the power measured in the reflected and transmitted paths with the subscripts $\mathrm{R}$ and $\mathrm{T}$, respectively. Behind the PBC the total reflected $\left(P_{\mathrm{R}}\right)$ and transmitted $\left(P_{\mathrm{T}}\right)$ power components are

$$
\begin{aligned}
& P_{\mathrm{R}}(\varphi)=\left[P_{\mathrm{p}}(\varphi) R_{\mathrm{p}}+P_{\mathrm{s}}(\varphi) R_{\mathrm{s}}\right] V_{\mathrm{R}}, \\
& P_{\mathrm{T}}(\varphi)=\left[P_{\mathrm{p}}(\varphi) T_{\mathrm{p}}+P_{\mathrm{s}}(\varphi) T_{\mathrm{s}}\right] V_{\mathrm{T}} .
\end{aligned}
$$

The amplification factors $V_{\mathrm{R}}$ and $V_{\mathrm{T}}$ include the optical transmittances of the receiver and the electronic amplification in each channel. $P_{\mathrm{R}}$ and $P_{\mathrm{T}}$ are the quantities we actually record with the data acquisition. For the following it is convenient to introduce a relative amplification factor $V^{*}$ and the measured signal ratio $\delta^{*}$

$\delta^{*}(\varphi)=\frac{P_{\mathrm{R}}(\varphi)}{P_{\mathrm{T}}(\varphi)}, \quad V^{*}=\frac{V_{\mathrm{R}}}{V_{\mathrm{T}}}$.

With eqs. (6)-(8), we achieve

$\delta^{*}(\varphi)=V^{*} \frac{\left[1+\delta^{\mathrm{v}} \tan ^{2}(\varphi)\right] R_{\mathrm{p}}+\left[\tan ^{2}(\varphi)+\delta^{\mathrm{v}}\right] R_{\mathrm{s}}}{\left[1+\delta^{\mathrm{v}} \tan ^{2}(\varphi)\right] T_{\mathrm{p}}+\left[\tan ^{2}(\varphi)+\delta^{\mathrm{v}}\right] T_{\mathrm{s}}}$.

\subsection{Calibration}

To retrieve the total backscatter power $P$ and $\delta^{v}$ from the measurements $P_{\mathrm{R}}$ and $P_{\mathrm{T}}$ with eqs. (3)-(7), we need $V^{*}$, which we can get from calibration measurements in different ways and using eq. (9) in the following form

$V^{*}=\frac{\left[1+\delta^{\mathrm{v}} \tan ^{2}(\varphi)\right] T_{\mathrm{p}}+\left[\tan ^{2}(\varphi)+\delta^{\mathrm{v}}\right] T_{\mathrm{s}}}{\left[1+\delta^{\mathrm{v}} \tan ^{2}(\varphi)\right] R_{\mathrm{p}}+\left[\tan ^{2}(\varphi)+\delta^{\mathrm{v}}\right] R_{\mathrm{s}}} \delta^{*}(\varphi)$.

For $\varphi=0^{\circ}$, it follows from eq. (10)

$V^{*}=\frac{\left(T_{\mathrm{p}}+\delta^{\mathrm{v}} T_{\mathrm{s}}\right)}{\left(R_{\mathrm{p}}+\delta^{\mathrm{v}} R_{\mathrm{s}}\right)} \delta^{*}\left(0^{\circ}\right)$.

With known $\delta^{v}$ in some range of the lidar signal, we can determine $V^{*}$ already from a regular measurement with eq. (11), which we call the ' $0{ }^{\circ}$-calibration'. The linear depolarization ratio $\delta^{\mathrm{m}}$ of air molecules is well known (Behrendt and Nakamura, 2002), and thus, we could use an aerosol-free lidar range in the free troposphere were $\delta^{\mathrm{v}}=\delta^{\mathrm{m}}$. But already a very low amount of strong depolarizing aerosols, like dust or ice crystals in the assumed clean range, causes large errors of $\delta^{v}$ and thus of $V^{*}$. Furthermore, several instrumental

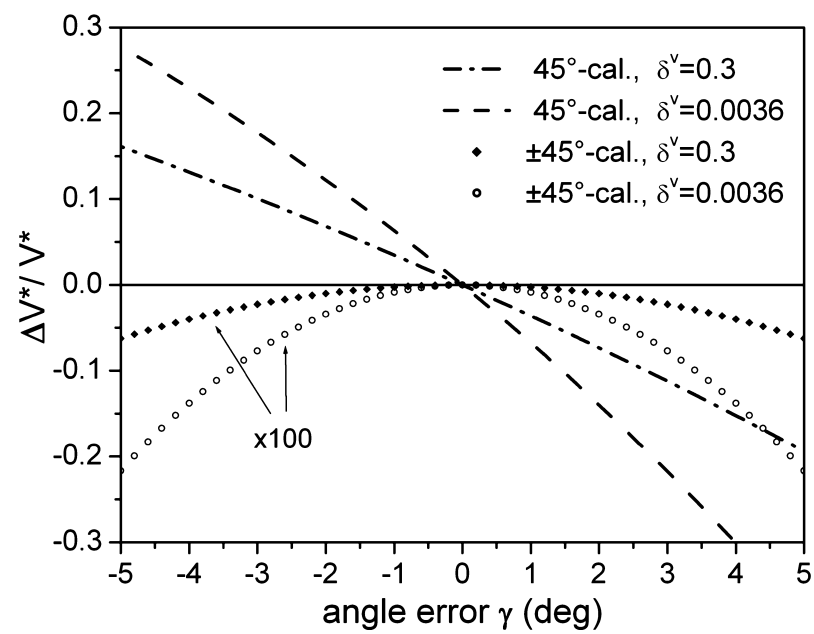

Fig. 2. Relative errors of $V^{*}$ over the calibration angle error $\gamma$ (see text) calculated using eqs. (9), (10), (12) and (13), with $T_{\mathrm{p}}=0.95, R_{\mathrm{p}}=$ $0.05, R_{\mathrm{S}}=0.99$ and $T_{\mathrm{s}}=0.01$ for $\delta^{\mathrm{v}}=0.0036$ (clean air) and $\delta^{\mathrm{v}}=$ 0.30 (desert dust). The $\pm 45^{\circ}$-calibration errors are multiplied by a factor of 100 .

uncertainties can add large errors, especially with this calibration method as described in the Appendix. More reliable calibration methods use the fact that $\tan ^{2}\left( \pm 45^{\circ}\right)=1$, which makes $P_{\mathrm{p}}=P_{\mathrm{s}}$ in eq. (6), and from eq. (9) we get for $\varphi=+45^{\circ}$ or $\varphi=-45^{\circ}$,

$V^{*}=\frac{T_{\mathrm{p}}+T_{\mathrm{s}}}{R_{\mathrm{p}}+R_{\mathrm{s}}} \delta^{*}\left( \pm 45^{\circ}\right)$,

which is independent of $\delta^{v}$. We call this method the $45^{\circ}$ calibration'. However, it is difficult to measure the exact angle of the plane of polarization of a laser beam and the alignment relative to the polarizing beamsplitter cube. An error $\gamma$ from $\varphi= \pm 45^{\circ}$, of the order of $1^{\circ}$, has to be assumed causing a large error in $V^{*}$ depending on $\delta^{v}$ (see Fig. 2). But if we calculate $V^{*}$ from two subsequent measurements at exactly $90^{\circ}$ difference, that is, $\varphi=+45^{\circ}+\gamma$ and $\varphi=-45^{\circ}+\gamma$ :

$V^{*}=\frac{T_{\mathrm{p}}+T_{\mathrm{s}}}{R_{\mathrm{p}}+R_{\mathrm{s}}} \sqrt{\delta^{*}\left(+45^{\circ}\right) \times \delta^{*}\left(-45^{\circ}\right)}$,

it can be shown that the errors compensate each other very well over a large range of $\gamma$ (see Fig. 2). We call this method the ' $\pm 45^{\circ}$-calibration'. The exact $90^{\circ}$ difference can be achieved with high accuracy by means of, for example, mechanical limit stops (portable lidar system, POLIS; Deutsches Zentrum für Luft- und Raumfahrt, High Spectral Resolution Lidar, DLRHSRL) or a motorized rotation mount (multichannel lidar system, MULIS).

The $45^{\circ}$-calibration is based on the fact that $P_{\mathrm{p}}=P_{\mathrm{s}}$ are made equal, which can also be achieved by using a polarizing sheet filter in front of the $\mathrm{PBC}$ at $\varphi=+45^{\circ}$ or $-45^{\circ}$ (see Fig. 3). If the polarizing filter has a negligible small transmission in the cross-polarized plane $\left(\mathrm{k} 2<10^{-4}\right)$, eqs. (12) and (13) are still valid, and the calibration errors are similar to those in Fig. 2. 


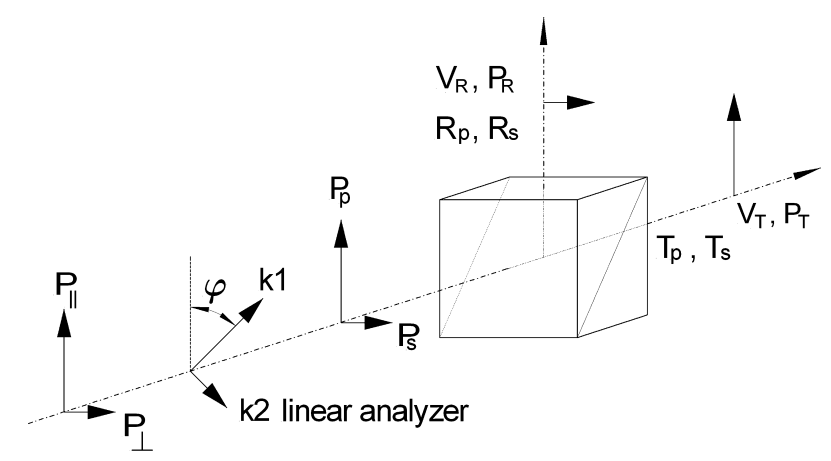

Fig. 3. Signal power components in a receiver of a depolarization lidar with an additional linear analyser (polarizing sheet filter) with transmittances parallel $(\mathrm{k} 1)$ and perpendicular $(\mathrm{k} 2)$ to the incident linear polarized light. The other components are as described in Fig. 1.

MULIS and POLIS used the advanced two-angle $\pm 45^{\circ}$ calibration method with different techniques for the rotation of the polarization, and the DLR-HSRL used the one angle $45^{\circ}$-calibration method. For Backscatter Extinction lidar-Ratio Temperature Humidity profiling Apparatus (BERTHA), the $45^{\circ}$ calibration with a polarizing sheet filter was applied.

\subsection{Retrieval of the linear volume depolarization ratio $\delta^{v}$}

Once $V^{*}$ is known, we get $\delta^{v}$ with eqs. (5) and (6), for a regular measurements at $\varphi=0^{\circ}$ :

$\delta^{\mathrm{v}}=\frac{P_{\perp}}{P_{\|}}=\frac{P_{\mathrm{s}}}{P_{\mathrm{p}}}, \quad \varphi=0^{\circ}$.

As for commercial PBCs, $R_{\mathrm{S}}$ is usually much closer to 1 than $T_{\mathrm{p}}$, the noise and error caused by the cross-talk from the strong parallel-polarized signal to the weaker cross-polarized signal are reduced if the parallel polarized signal is detected in the reflected s-branch of the PBC. For this setup $\varphi=90^{\circ}$, and we get

$\delta^{\mathrm{v}}=\frac{P_{\perp}}{P_{\|}}=\frac{P_{\mathrm{p}}}{P_{\mathrm{s}}}, \quad \varphi=90^{\circ}$.

From eqs. (5)-(8) follows

$\frac{P_{\mathrm{s}}}{P_{\mathrm{p}}}=\frac{\frac{\delta^{*}}{V^{*}} T_{\mathrm{p}}-R_{\mathrm{p}}}{R_{\mathrm{s}}-\frac{\delta^{*}}{V^{*}} T_{\mathrm{s}}}$

and

$P=P_{\mathrm{p}}+P_{\mathrm{s}}=\frac{V^{*}\left(R_{\mathrm{s}}-R_{\mathrm{p}}\right) P_{\mathrm{T}}+\left(T_{\mathrm{p}}-T_{\mathrm{s}}\right) P_{\mathrm{R}}}{V_{R}\left(T_{\mathrm{p}} R_{\mathrm{s}}-R_{\mathrm{p}} T_{\mathrm{s}}\right)}$.

The knowledge of $V_{\mathrm{R}}$ is not necessary, as we only need a relative signal for the lidar signal inversion with the Fernald/Klett retrieval (Klett, 1985; Fernald, 1984), and thus we can set it to $V_{\mathrm{R}}=1$. In case the parameters of the polarizing beamsplitter cube are

$T_{\mathrm{s}}=1-R_{\mathrm{s}}, \quad R_{\mathrm{p}}=1-T_{\mathrm{p}}$, which can be assumed for commercial PBCs, the total signal $P$ is retrieved from

$P=P_{\mathrm{p}}+P_{\mathrm{s}}=V^{*} P_{\mathrm{T}}+P_{\mathrm{R}}$.

\subsection{Retrieval of the linear particle depolarization ratio $\delta^{\mathrm{p}}$}

The $\delta^{\mathrm{p}}$ can be calculated from eqs. (2)-(5) using

$\delta^{\mathrm{p}}=\frac{\beta_{\perp}^{\mathrm{p}}}{\beta_{\|}^{\mathrm{p}}}=\frac{\left(1+\delta^{\mathrm{m}}\right) \delta^{\mathrm{v}} \boldsymbol{R}-\left(1+\delta^{\mathrm{v}}\right) \delta^{\mathrm{m}}}{\left(1+\delta^{\mathrm{m}}\right) \boldsymbol{R}-\left(1+\delta^{\mathrm{v}}\right)}$

(Biele et al., 2000), with the height in dependent linear depolarization ratio of air molecules:

$\delta^{\mathrm{m}}=\frac{\beta_{\perp}^{\mathrm{m}}}{\beta_{\|}^{\mathrm{m}}}$

which can be determined with high accuracy (Behrendt and Nakamura, 2002). The backscatter ratio $\mathbf{R}$ can be retrieved from the total signal $P$ using, for example, the Fernald/Klett inversion with a reference value $\beta^{\mathrm{p}}\left(r_{0}\right)$ at a reference range $r_{0}$ and known range-dependent lidar ratios $S$

$S=\frac{\beta^{\mathrm{P}}}{\alpha^{\mathrm{p}}}$,

where $\alpha^{\mathrm{p}}$ is the particle extinction coefficient. $S(r)$ must be retrieved by an additional measurement, for example, with a Raman channel (Tesche et al., 2008) or a HSRL (Esselborn et al., 2008). The values of $\delta^{v}$ and $\mathrm{R}$ are subject to systematic and statistical (noise) errors. A detailed error propagation analysis can be found in the Appendix.

\section{Polarization lidar in SAMUM}

The linear depolarization ratio of the dust particles was measured during SAMUM with four lidar systems at four wavelengths:MULIS at $532 \mathrm{~nm}$;POLIS at $355 \mathrm{~nm}$ (both from Munich);BERTHA at $710 \mathrm{~nm}$ (Leipzig) and the airborne DLR HSRL at 532 and $1064 \mathrm{~nm}$. MULIS and BERTHA were located at the airport of Quarzazate $\left(1133 \mathrm{~m}\right.$ a.s.1., $\left.30.938^{\circ} \mathrm{N},-6.907^{\circ} \mathrm{E}\right)$ about $10 \mathrm{~m}$ apart from each other and POLIS at about $100 \mathrm{~m}$ distance. All three ground based systems can change the zenith angle of the sounding (scanning capability), which possibility was used frequently. We assume that the profiles of the different lidar systems are well comparable as orographical effects of the surrounding are negligible and the dust layer was mostly sufficiently homogeneous over the considered periods. The DLRHSRL was installed on board the DLR Falcon airplane, which flew several times over the ground based lidars, with high spatial accuracy. For the temporal averaging of these measurements, care was taken to consider only sections of the time-series with comparably small changes in the lidar profiles. Owing to a lack of adequate reference sources, MULIS and POLIS are described in 
Table 1. System parameters of the depolarization channels of the lidar systems

\begin{tabular}{|c|c|c|c|c|c|}
\hline & & POLIS & MULIS & BERTHA & DLR-HSRL \\
\hline Laser/Receiver & & Biaxial & Biaxial & Coaxial & Coaxial \\
\hline Laser & & Brilliant Ultra & Continuum, Surelite II & Ti:Saphire, Solar TII Ltd. CF 125 & Nd:YAG \\
\hline Wavelengths & $(\mathrm{nm})$ & 355 & 532 & 710 & 1064,532 \\
\hline Pulse energy & $(\mathrm{mJ})$ & 7.8 & 50 & 20 & 220,100 \\
\hline Repetition rate & $(\mathrm{Hz})$ & 20 & 10 & 30 & 100 \\
\hline Beam divergence & $(\mathrm{mrad})$ & 0.69 & 0.6 & $<0.3$ & 0.5 \\
\hline Telescope & & Dall-Kirkham & Cassegrain & Cassegrain & Cassegrain \\
\hline Diameter & (m) & 0.2 & 0.3 & 0.53 & 0.35 \\
\hline Focal length & $(\mathrm{m})$ & 1.2 & 0.96 & 3 & 5 \\
\hline Field stop & $(\mathrm{mrad})$ & 2.5 & 0 to 3 , adjustable & 0.6 & 1 \\
\hline \multicolumn{6}{|l|}{ Receiver optics } \\
\hline Interference filter bandwidth & $(\mathrm{nm})$ & 1.0, fwhm & 1.1, fwhm & 0.4 , fwhm & 1.0, fwhm \\
\hline $\operatorname{PBC} T_{\mathrm{p}}$ & & 0.9521 & 0.9831 & 0.95 & 1 \\
\hline $\mathrm{PBC} R_{\mathrm{S}}$ & & 0.9985 & 0.9965 & 0.999 & 1 \\
\hline Depol.-calibration method & & $\pm 45^{\circ}$ manual & $\pm 45^{\circ}$ wave plate & $45^{\circ}$ polarizer & $45^{\circ}$ manual \\
\hline
\end{tabular}

more detail in the following. For the DLR-HSRL and BERTHA, the details regarding the depolarization measurements complement the descriptions in the references mentioned below. Table 1 gives a summary of the relevant lidar system parameters.

\subsection{MULIS}

MULIS is a mobile, five wavelength lidar system with backscatter channels at 355, 532 and $1064 \mathrm{~nm}$ and Raman channels at 387 and $607 \mathrm{~nm}$. The Nd:YAG laser fundamental wavelength is frequency doubled and tripled by means of Potassium Dideuterium Phosphate $\left(\mathrm{KD}^{*} \mathrm{P}\right)$ crystals, and the output at $532 \mathrm{~nm}$ is assumed to be perfectly linear polarized. The adjustable filed stop (TS in Fig. 4) is used to decrease the field of view and with that, the signal power in the near range during the calibration measurements, because at $\varphi= \pm 45^{\circ}$ (Fig. 1), the signal in the cross-polarized channel can increase by an order of magnitude. Such a high signal exceeds the linear range of the data acquisition, especially that of the preamplifier, which would introduce signal distortions and errors in $V^{*}$, which are very difficult to assess. To minimize diattenuation and polarization effects of the dichroic beamsplitters, all optical coatings are custom-designed (Laseroptik, Germany). For the same reason, the beamsplitters BS1 to BS4 are used at $30^{\circ}$ reflection angle (see Fig. 4). To reduce cross-talk, the custom-made PBC (Optarius, UK) has high transmittance $T_{\mathrm{p}}$ and high reflection $R_{\mathrm{s}}$, and $P_{\|}$is detected in the reflected branch $P_{\mathrm{R}}$ of the $\mathrm{PBC}$ (see eq. 15). A cemented, true zero-order half-wave plate at $532 \mathrm{~nm}$ (Casix, China) is used in front of the $\mathrm{PBC}$ to rotate the plane of polarization with a verified accuracy and repeatability of better than $0.1^{\circ}$. The accuracy of the $\varphi=0^{\circ}$ position is better than $\pm 0.2^{\circ}$, and a $\pm 45^{\circ}$-calibration was performed every time the lidar setup had been changed. The detectors are Hamamatsu R7400 PMTs in the depolarization

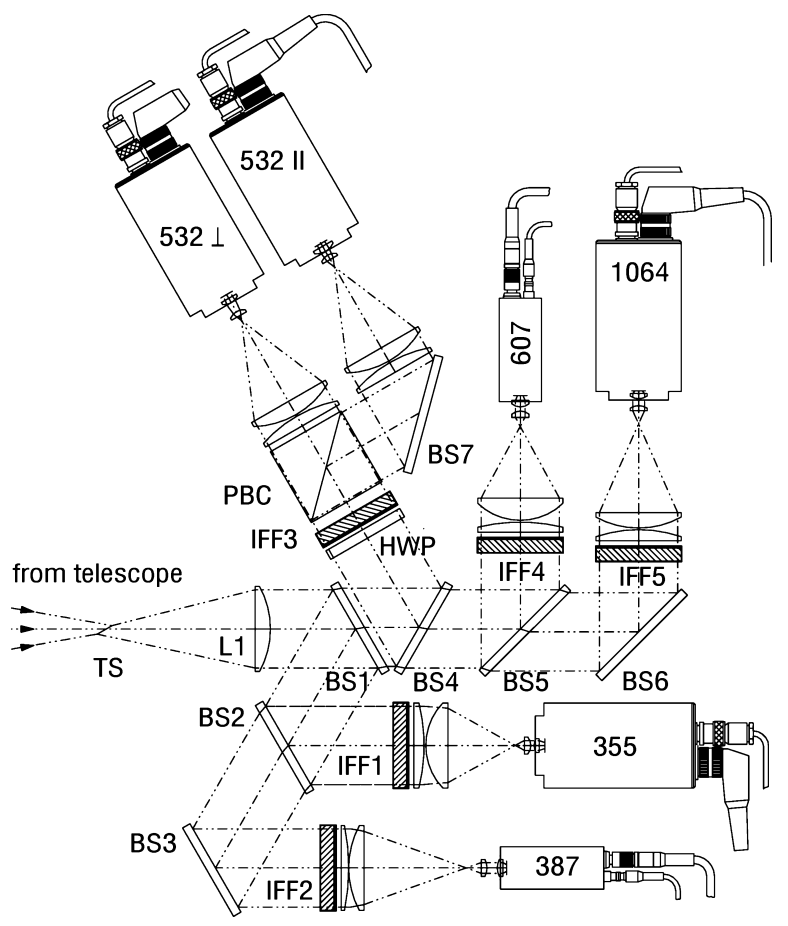

Fig. 4. Optical setup of the MULIS receiver with analog backscatter channels at $355 \mathrm{~nm}, 532 \mathrm{~nm}$ parallel- and cross- polarized, $1064 \mathrm{~nm}$ and Raman channels at 387 and $607 \mathrm{~nm}$. TS, tilted slit diaphragm; L1, collimating lens; BS\#, dichroic beamsplitters (BS3, 6 and 7 are used as mirrors); IFF\#, interference filter; $\mathrm{PBC}$, polarizing beamsplitter cube at $532 \mathrm{~nm}$ and HWP, half-wave plate at $532 \mathrm{~nm}$ for the calibration of the depolarization channels.

channels. The sensitivity of individual channels was adjusted with absorbing neutral density filters (Schott). The preamplifier stages of the 12 bit $\left(P_{\mathrm{R}}, P_{\|}\right)$and 14 bit $\left(P_{\mathrm{T}}\right)$ ADC-boards (Spectrum GmbH, Germany) were optimized regarding signal 


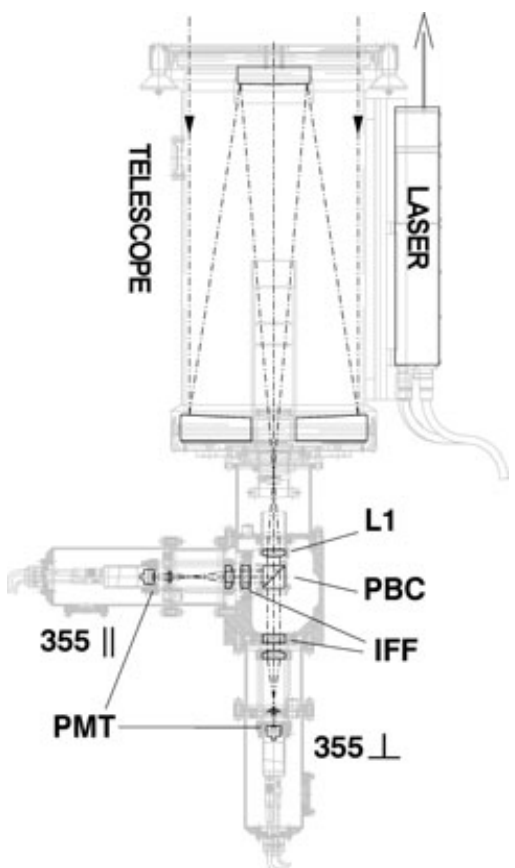

Fig. 5. Schematic of POLIS with depolarization module. L1, collimating lens; PBC, polarizing beamsplitter cube; IFF, interference filter and PMT, photomultiplier.

linearity, with signal distortions in the clean, free troposphere below $\pm 20 \mu \mathrm{V}$ after near-range signal peaks of about $50 \%$ of the full preamplifier range of $1 \mathrm{~V}$. Due to weak signals in the Raman channels and the limited dynamic range of the photocounting detection, the extinction coefficient $\alpha$ and the lidar ratio $S$ were not retrieved from MULIS measurements but were adopted from the much more accurate DLR-HSRL measurements (Esselborn et al., 2008) or from BERTHA (Tesche et. al., 2008).

\subsection{POLIS}

The portable lidar system POLIS is a small, rugged, two-channel lidar system with several modular detection options. During SAMUM, it measured the parallel- and cross-polarized signals at $355 \mathrm{~nm}$ or the backscatter at $355 \mathrm{~nm}$ and the $\mathrm{N}_{2}$-Raman shifted wavelength at $387 \mathrm{~nm}$. The two different detector modules are rigidly mounted to the telescope by means of a superfinished circular flange with an angular scale, which allows the manual $\pm 45^{\circ}$-rotation of the whole depolarization detector module with respect to the laser polarization with an estimated accuracy of $\pm 1^{\circ}$ (Fig. 5). The parallel-polarized signal $P_{\|}$is detected in the reflected channel $P_{\mathrm{s}}$ of the PBC (eq. 15). Absorbing neutral density filters are used to adjust the sensitivity ranges of the individual detection channels. The data acquisition consists of Licel PMT-detector modules with combined analog-photocounting recording of the signals. A constant lidar ratio of $S=55 \pm 10 \mathrm{sr}$ was used for the depolarization retrieval. Other technical details of this system can be found in Heese et al. (2002).

\subsection{DLR-HSRL}

A detailed description of the DLR-HSRL system and an assessment of its measurement accuracy can be found in Esselborn et al. (2008) and Esselborn et al. (2008). Besides the direct extinction measurement at $532 \mathrm{~nm}$ by means of the HSRL technique, the system is designed to measure the linear depolarization ratio at 1064 and $532 \mathrm{~nm}$. A dichroic beamsplitter in the receiver module is used to spectrally separate the backscatter signals at 1064 and $532 \mathrm{~nm}$, and polarizing beamsplitter cubes (PBC) are used to separate the parallel- $\left(P_{\|}\right)$and cross-polarized $\left(P_{\perp}\right)$ signals. The residual cross-talk between $P_{\|}$and $P_{\perp}$ due to $R_{\mathrm{p}}$ and $T_{\mathrm{s}}$ are here reduced by means of additional PBCs in each channel behind the first PBC. Thus, we can assume

$R_{\mathrm{p}}=T_{\mathrm{s}}=0 \quad$ and $\quad R_{\mathrm{s}}=T_{\mathrm{p}}=1$

in all formulas. The reduction in transmittance and reflectance is included in the corresponding sensitivity factors $\eta$. The depolarization and calibration formulae for the $1064 \mathrm{~nm}$ branch are as described above, but in the $532 \mathrm{~nm}$ branch, the received atmospheric backscatter is first split with a PBC into its parallel- and cross-polarized components, and then the parallel-olarized signal is split again with a non-polarizing beamsplitter into the socalled combined channel $\left(P_{\|}\right)$and the molecular channel $\left(P_{\|}^{\mathrm{M}}\right)$. Hence the linear volume depolarization ratio $\delta^{\mathrm{v}}$ must be calculated from

$\delta^{\mathrm{v}}=\frac{\eta_{\|}^{\mathrm{C}}}{\eta_{\perp}} \frac{P_{\perp}}{P_{\|}^{\mathrm{C}}}$,

and the amount of total backscatter $P$ from

$P=P_{\|}^{\mathrm{C}}+\frac{\eta_{\|}^{\mathrm{C}}}{\eta_{\perp}} P_{\perp}$.

Comparing with eq. (3), (5) and (8), we see that here,

$V^{*}=\frac{\eta_{\|}^{\mathrm{C}}}{\eta_{\perp}}, \quad \delta^{*}(\varphi)=\frac{P_{\mathrm{R}}(\varphi)}{P_{\mathrm{T}}(\varphi)}=\frac{P_{\perp}(\varphi)}{P_{\|}^{\mathrm{C}}(\varphi)}$.

With the DLR-HSRL, the particle extinction profile $\alpha$ and the lidar ratio $S$ at $532 \mathrm{~nm}$ can be retrieved directly from the HSRL-measurements, the backscatter ratio $\mathbf{R}$ can be calculated, and finally, the linear particle depolarization ratio $\delta^{\mathrm{p}}$ from eq. (20).

\subsection{BERTHA}

Details of the system are described in Althausen et al. (2000), and Tesche et al. (2008). BERTHA was not designed to provide high-quality polarization measurements. The goal of BERTHA's depolarization measurements at $710 \mathrm{~nm}$ is to separate water from ice clouds, to identify mixed-phase clouds and to discriminate 
desert dust from other less depolarizing aerosols like urban haze or maritime air. After collection with the primary telescope mirror, the photons have to pass five optical elements (reflecting mirrors and dichroic beamsplitters) before reaching the PBC, which reflects the parallel- $\left(P_{\|}\right)$and transmits the cross-polarized signal components at $\sim 710 \mathrm{~nm}$ (eq. 15). The $45^{\circ}$-calibrations with a polarizing sheet filter before the $\mathrm{PBC}$ were performed during several SAMUM evening lidar sessions. The optical elements, located between the $P_{\|}$- and the $P_{\mathrm{p}}$-planes before the polarizing sheet filter in Fig. 3, show a significant diattenuation $D=0.726 \pm 2 \%$, which is not included in the depolarization calibration but was determined with separate measurements. Hence eq. (15) for the retrieval of $\delta^{v}$ must be complemented:

$\delta^{\mathrm{v}}=\frac{P_{\perp}}{P_{\|}}=D \frac{P_{\mathrm{p}}}{P_{\mathrm{s}}}, \quad \varphi=90^{\circ}$.

\subsection{Sunphotometer and radiosonde}

Two sunphotometers were installed close to the ground based lidar systems (SSARA and AERONET; see Toledano et al., 2008, and D. Müller, personal communication, 2008, respectively). SSARA measurements are available in one-minute steps and were therefore used for comparison with the MULIS measurements. The AERONET data was used for the evaluation of the DLR-HSRL 1064 nm channel (see Appendix). The Ångström exponent (AE) is derived from the wavelength- $(\lambda)$ dependent aerosol (i.e. particle) optical depth (AOD) from the fomula

$A O D(\lambda)=$ const. $\times \lambda^{-A E}$.

Local radiosondes were launched during SAMUM at least twice per day, at about 10 UTC and 20 UTC. The radiosonde data were used to calculate the molecular backscatter coefficients $\beta^{\mathrm{m}}(r)$.

\section{Observations}

The paper presents linear particle depolarization ratio $\delta^{\mathrm{p}}$ measurements at four wavelengths. However, MULIS (532 nm) and the airborne DLR-HSRL (532 and $1064 \mathrm{~nm}$ ) provided the most accurate measurements of the linear depolarization ratio. These lidar measurements represent the backbone of the entire SAMUM polarization lidar activity. First, we compare the height resolved profiles of $\delta^{\mathrm{p}}$ of all lidars at four dates with coincident measurements in Fig. 6. The lidar ratios $S$ used for the depolarization retrieval of MULIS at $532 \mathrm{~nm}$ were adopted from the coincident DLR-HSRL measurements (displayed in Fig. 6 as broken lines) with errors in the range of $\pm 5 \mathrm{sr}$. For non-coincident measurements $S$ is assumed to be $50 \mathrm{sr} \pm 10 \mathrm{sr}$. The DLR-HSRL can use its measurement of the extinction coefficient directly for the $532 \mathrm{~nm}$ depolarization as shown in the Appendix (eq. A.15), and for the $1064 \mathrm{~nm}$ channel, the extinction values were scaled from the $532 \mathrm{~nm}$ values using the AE from the local AERONET sunphotometer. For POLIS and BERTHA, a constant $S=55 \mathrm{sr}$ \pm 10 sr was assumed. The particle backscatter coefficients $\beta^{\text {p }}$ from MULIS $532 \mathrm{~nm}$ in Fig. 6 indicate the structure and extent of the dust layer.

The MULIS and DLR-HSRL $\delta^{\mathrm{p}}$ profiles agree very well on 19 May, 28 May and 3 June (Fig. 6) with a mean relative difference of $2.4 \%$. On 4 June, an almost constant offset of about $11 \%$ can be seen, which comes from errors of the regular calibration of one or both instruments, explained in detail in the Appendix; but the profiles still agree within the error bars. Error bars are commonly considered as uncertainties due to statistical noise, and the true mean value is assumed to be close to the apparent mean with a probability given by the statistical nature of the signals, which often is assumed to be Gaussian. In this study the error bars represent pure systematic uncertainties due to temporally constant system errors during the measurements, and thus, the true profiles can be shifted anywhere inside the error bars with the same probability. The 4 June case clearly points that out. The statistical error is comparably small, even more in the mean values over the dust layer and is therefore not shown. The direct comparison of the two lidars at $532 \mathrm{~nm}$ serves as a quality assurance of both systems and shows the meaningfulness of the error analysis. This also holds for the DLR-HSRL $1064 \mathrm{~nm}$ values, as they are measured with the same lidar and analysed with the same error propagation analysis. The errors of POLIS are large, and comparing the POLIS profils with the others, a range-dependent signal deviation seems probable.

The mean values over the dust layer and statistics of the measurements in Fig. 6, and additionally for a DLR-HSRL measurement on 20 May, are plotted over the wavelength in Fig. 7. Without the height-variance, the excellent agreement of the MULIS and DLR-HSRL at $532 \mathrm{~nm}$ appears clearly, as well as the slight apparent decrease of the mean $\delta^{\mathrm{p}}$ values of the DLRHSRL from $0.31 \pm 0.03$ at $532 \mathrm{~nm}$ to $0.27 \pm 0.04$ at $1064 \mathrm{~nm}$. The error bars allow for slopes of $\delta^{\mathrm{p}}$ over wavelength between $+0.05 \times 10^{-3}$ and $-2.1 \times 10^{-3} \mathrm{~nm}^{-1}$. Due to the larger error bars, the 355 and $710 \mathrm{~nm}$ values were not considered. However, for the whole wavelength range between 355 and $1064 \mathrm{~nm}$ the minimum and maximum $\delta^{\mathrm{p}}$ values in Fig. 7 (including the error bars) are confined between 0.17 and 0.39 .

Using microphysical properties as input parameters, the optical properties of mineral dust, including the linear particle depolarization ratio $\delta^{\mathrm{p}}$, can be modelled by means of T-matrix method, assuming that the particles can be approximated by spheroids (Wiegner et al., 2008). For the 19 May case, those microphysical properties are available from airborne in situ measurements in the dust layer in the vicinity of Ouarzazate at 11:23-12:06 UT (Kandler et al., 2008). The simulations for this day show a monotonic increase from $\delta^{\mathrm{p}}=0.207$ to 0.265 for the wavelength range from 355 to $1064 \mathrm{~nm}$. Compared with the measurements (Fig. 7), the simulated $\delta^{\mathrm{p}}$ for 

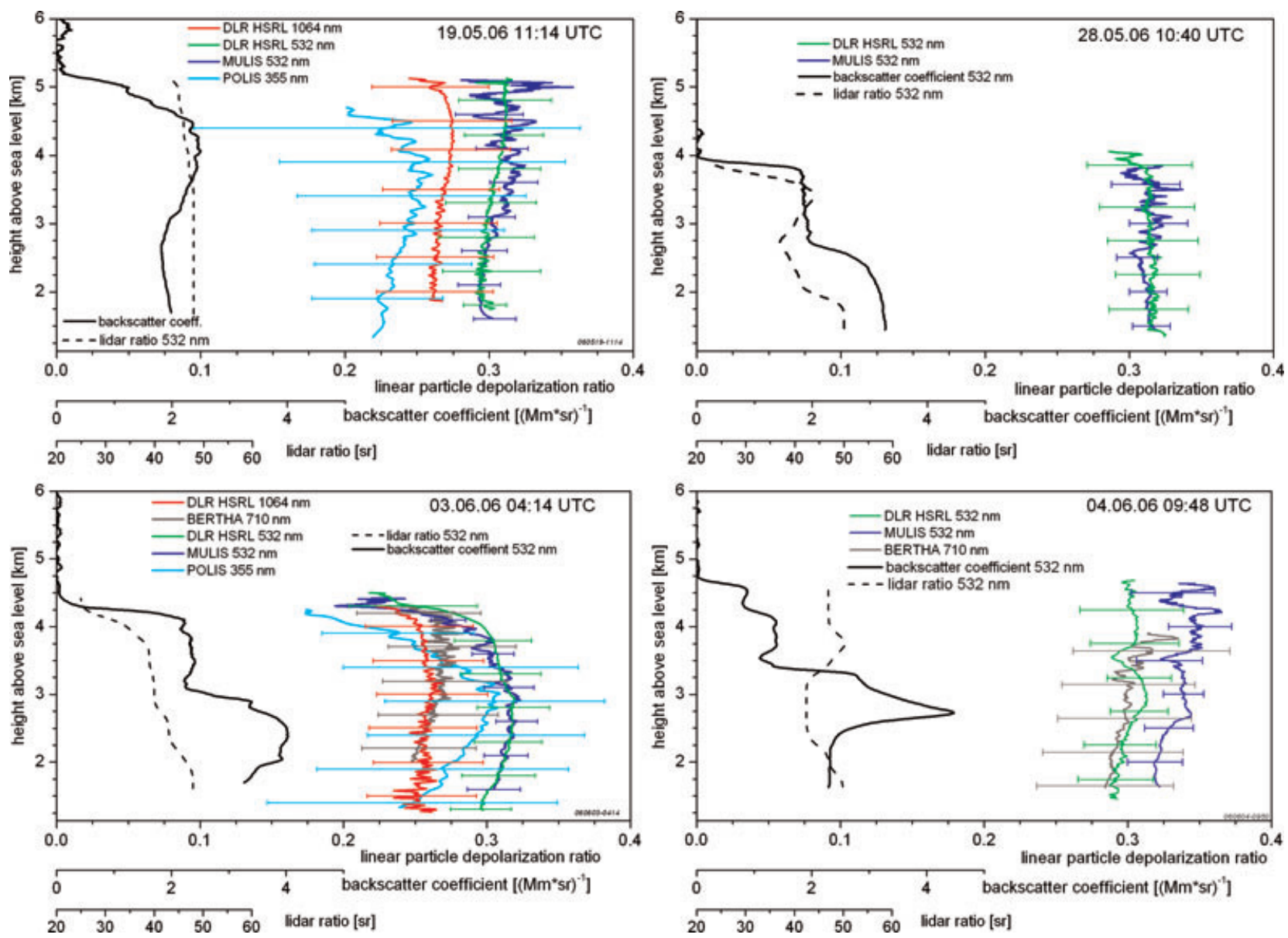

Fig. 6. Particle linear depolarization ratio profiles on 19 and 20 May and 3 and 4 June 2006 at several wavelengths, above Quarzazate at times of Falcon overflights. Average times of the individual instruments are listed in Table 2. The error bars indicate the systematic uncertainties. The MULIS $532 \mathrm{~nm}$ backscatter coefficient was calculated using the Klett inversion with lidar ratios adapted from the DLR-HSRL. HSRL vertical resolution is $15 \mathrm{~m}$.

$1064 \mathrm{~nm}$ are within the uncertainty range of the lidar measurements. At $532 \mathrm{~nm}$, the simulated $\delta^{\mathrm{p}}=0.235$ is outside the range of the systematic errors of the lidar systems with measured $\delta^{\mathrm{p}}=0.30 \pm 0.04$ on 19 May, and at $355 \mathrm{~nm}$ the large systematic lidar errors degrade the significance of a direct comparison. The simulation results are discussed in detail in Wiegner et al. (2008).

The linear depolarization ratio was measured with MULIS continuously during SAMUM. Retrievals of the linear particle depolarization ratio $\delta^{\mathrm{p}}$ at selected dates, together with error bars and statistical information are displayed in Fig. 8 and listed in Table 2, together with the measurements from the other lidars from Fig. 7. The full ranges of the $\delta^{\mathrm{p}}$ values are often asymmetric to the mean towards smaller $\delta^{\mathrm{p}}$. These smaller values mostly stem from the dust layer top caused by temporal averaging of the lidar measurements with changing dust layer top height. This effect can be seen in Fig. 6 on 3 June. Two dust layers could be distinguished in different heights on 30 May, 20:20 UTC, with distinctly different $\delta^{\mathrm{p}}$ : between 0.35 and $1.2 \mathrm{~km}$ a.s.l., extremely low particle linear depolarization ratios between 0.177 and 0.200 , and between 1.65 to $2.3 \mathrm{~km}$ a.s.1., higher ratios between 0.266 and 0.283 , indicating different air masses with different particle characteristics. The corresponding values are listed in Table 2 additionally to the overall mean together with the height ranges. In Fig. 8 the two layers are discerned.

The AOD at $500 \mathrm{~nm}$ and the AE (440-870 nm) derived from the SSARA measurements temporally closest to the MULIS measurements are displayed on top of Fig. 8. The AOD and AE values and $\mathrm{AE}$ errors in Table 2 are the mean values and standard deviations, respectively, over the periode of the MULIS measurement, as indicated in Table 2. For nighttime, when no sunphotometer data were available, the AE values were interpolated and the AE errors show the slope. Comparing the time-series in Fig. 8 we see low $\delta^{\mathrm{p}}$ and high $\mathrm{AE}$ in the shaded time periods, and high $\delta^{\mathrm{p}}$ and low AE else, whereas there is no evidence for a correlation between $\delta^{\mathrm{p}}$ and AOD, as expected. Figure 9 displays the linear particle depolarization ratio over the AE for the MULIS values from Table 2, with the mean values over both layers on 


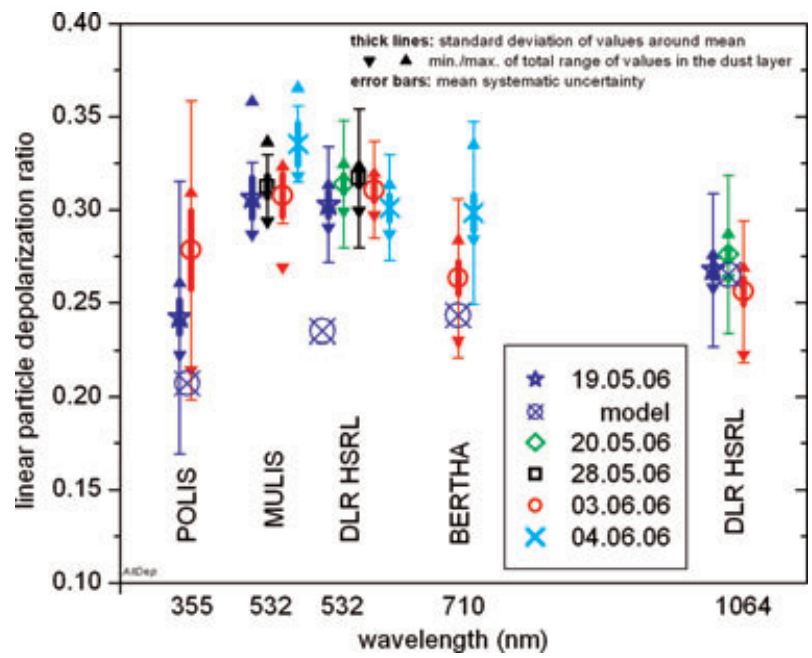

Fig. 7. Mean linear depolarization ratio of particles in the dust layer over the wavelength of the four lidar systems at four different dates during SAMUM 2006 and results of model calculations for the reference case 19 May 2006 (Wiegner et al., 2008). Triangles indicate the min. and max. of the measured values in the dust layer, and the thick lines show the standard deviation around the mean. The error bars indicate the systematic uncertainty of the mean. See also Table 2.
30 May and the shaded values as in Fig. 8. The mean $\delta^{\mathrm{p}}$ over the dust layers during dust phases (Knippertz et al., 2008) range between 0.27 and 0.35 , with corresponding AEs between 0.04 and 0.34 , whereas during the intermediate periods with low turbidity (AOD below about 0.1 ), the mean $\delta^{\mathrm{p}}$ ranges between 0.21 and 0.25 , with $\mathrm{AE}$ from 0.65 to 1.00 , except for the 23 May case with a mean $\delta^{\mathrm{p}}$ of 0.22 and $\mathrm{AE}$ of 0.35 , which must be investigated separately. The negative correlation of $\delta^{\mathrm{p}}$ with $\mathrm{AE}$ indicates that the relative influence of pronounced non-spherical particles (high $\delta^{\mathrm{p}}$ ) on the backscattered light decreases when $\mathrm{AE}$ increases. Ångström exponents $>0.5$ indicate the presence of a considerable amount of non-dust particles, probably (almost spherical) anthropogenic particles. Such particles cause $\delta^{\mathrm{p}}$ of the order of 0.05 (Murayama et al., 2003). However, the $\delta^{\mathrm{p}}$ values between 0.21 and 0.25 in the intermediate periods with rather clean air masses (low AOD) indicate that the air still carries some particles with high $\delta^{\mathrm{p}}$, probably from local dust sources. The mean values over the dust phases and intermediate phases are summarized in Table 3.

Most papers in the literature deal with depolarization observations in aged dust after long-range transport. This dust may be partly or completely mixed with maritime particles, anthropogenic pollution or biomass-burning smoke (e.g. Sakai et al.,

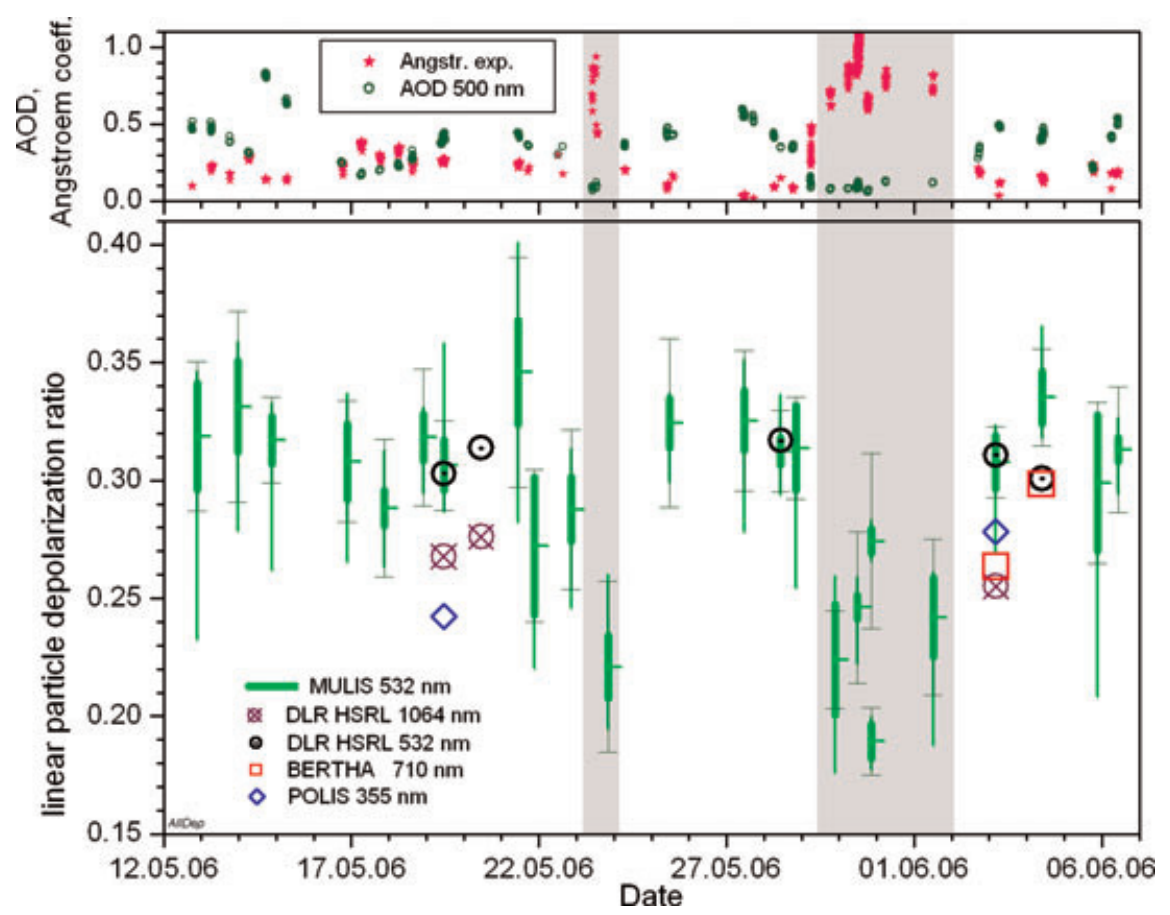

Fig. 8. Mean linear particle depolarization ratio $\delta^{\mathrm{p}}$ in the dust layer over Quarzazate during the SAMUM 2006 period for selected dates (lower plot) and aerosol optical thickness at $500 \mathrm{~nm}$ and Ångström exponent (440-870 nm) from SSARA sun photometer at Quarzazate (upper plot). Only SSARA values at times close to the MULIS measurements are excerpted from the complete time-series (Toledano et al., 2008). For MULIS at $532 \mathrm{~nm}$ (green), the thick lines show the unweighted standard deviation around the mean linear particle depolarization ratio, the thin lines show the range of $\mathrm{min} / \mathrm{max}$ ratios and the error bars show the mean systematic uncertainty of an individual value in the min/max range. The statistical data for the DLR-HSRL, the POLIS and BERTHA are only shown (in Fig. 7) for the sake of clarity. Two time periods are shaded, with high Ångström exponents and corresponding low particle linear depolarization ratios. 
Table 2. Date and parameters of all of the measurements in Fig. 8

\begin{tabular}{|c|c|c|c|c|c|c|c|c|c|c|c|}
\hline & \multicolumn{2}{|c|}{ Measurements } & \multirow{2}{*}{$\begin{array}{l}\text { Elev. } \\
\left({ }^{\circ}\right)\end{array}$} & \multicolumn{5}{|c|}{ Linear particle depolarization ratio $\left(\delta^{\mathrm{p}}\right)$} & \multicolumn{2}{|c|}{ Ångström } & \multirow[t]{2}{*}{ Comments } \\
\hline & $\begin{array}{l}\text { From } \\
\text { (UTC) }\end{array}$ & $\begin{array}{c}\text { To } \\
\text { (UTC) }\end{array}$ & & Mean & Error & $S D$ & Min. & Max. & exponent & error & \\
\hline \multicolumn{12}{|l|}{ MULIS (532 nm) } \\
\hline 12 May 2006 & $21: 18$ & $21: 34$ & 90 & 0.32 & 0.03 & 0.023 & 0.23 & 0.35 & 0.126 & 0.009 & \\
\hline 13 May 2006 & $23: 11$ & $23: 16$ & 40 & 0.33 & 0.04 & 0.019 & 0.28 & 0.36 & 0.213 & 0.009 & \\
\hline 14 May 2006 & $20: 51$ & 21:01 & 90 & 0.32 & 0.02 & 0.010 & 0.26 & 0.33 & 0.135 & 0.001 & \\
\hline 16 May 2006 & $21: 18$ & $21: 35$ & 28 & 0.31 & 0.03 & 0.016 & 0.27 & 0.34 & 0.208 & 0.019 & \\
\hline 17 May 2006 & $20: 55$ & $21: 12$ & 45 & 0.29 & 0.03 & 0.008 & 0.26 & 0.31 & 0.265 & 0.007 & \\
\hline 18 May 2006 & $20: 25$ & $21: 54$ & 88 & 0.32 & 0.03 & 0.010 & 0.3 & 0.33 & 0.242 & 0.003 & \\
\hline 19 May 2006 & 11:04 & $11: 14$ & 88 & 0.31 & 0.02 & 0.011 & 0.29 & 0.36 & 0.263 & 0.008 & AOD 0.432 \\
\hline 21 May 2006 & $10: 14$ & $10: 50$ & 90 & 0.35 & 0.05 & 0.022 & 0.28 & 0.4 & 0.235 & 0.007 & AOD 0.44 \\
\hline 21 May 2006 & $21: 29$ & $22: 15$ & 45 & 0.27 & 0.03 & 0.029 & 0.22 & 0.3 & 0.239 & 0.005 & \\
\hline 22 May 2006 & $20: 35$ & $20: 45$ & 30 & 0.29 & 0.03 & 0.014 & 0.25 & 0.31 & 0.340 & 0.033 & \\
\hline 23 May 2006 & $19: 53$ & $20: 16$ & 28 & 0.22 & 0.04 & 0.013 & 0.2 & 0.26 & 0.350 & 0.016 & \\
\hline 25 May 2006 & 11:07 & $11: 28$ & 88 & 0.32 & 0.06 & 0.031 & 0.30 & 0.34 & 0.134 & 0.022 & \\
\hline 27 May 2006 & $11: 11$ & $11: 27$ & 45 & 0.33 & 0.03 & 0.013 & 0.28 & 0.35 & 0.039 & 0.002 & AOD 0.553 \\
\hline 28 May 2006 & $10: 37$ & $10: 41$ & 88 & 0.31 & 0.02 & 0.006 & 0.29 & 0.34 & 0.152 & 0.002 & AOD 0.350 \\
\hline 28 May 2006 & 20:01 & $20: 25$ & 88 & 0.31 & 0.02 & 0.018 & 0.25 & 0.33 & 0.117 & 0.015 & \\
\hline 29 May 2006 & 21:06 & $21: 22$ & 88 & 0.22 & 0.02 & 0.023 & 0.18 & 0.26 & 0.645 & 0.012 & \\
\hline 30 May 2006 & $11: 40$ & $11: 50$ & 40 & 0.25 & 0.03 & 0.005 & 0.22 & 0.26 & 1.000 & 0.009 & AOD 0.105 \\
\hline 30 May 2006 & $20: 20$ & $20: 38$ & 40 & 0.21 & 0.02 & 0.040 & 0.18 & 0.28 & 0.662 & 0.008 & $0.35-2.3 \mathrm{~km}$ \\
\hline 30 May 2006 & $20: 20$ & $20: 38$ & 40 & 0.19 & 0.01 & 0.007 & 0.18 & 0.2 & & & $0.35-1.2 \mathrm{~km}$ \\
\hline 30 May 2006 & $20: 20$ & $20: 38$ & 40 & 0.27 & 0.04 & 0.005 & 0.27 & 0.28 & & & $1.65-2.3 \mathrm{~km}$ \\
\hline 1 June 2006 & $11: 45$ & $12: 07$ & 40 & 0.24 & 0.03 & 0.017 & 0.19 & 0.26 & 0.740 & 0.047 & AOD 0.121 \\
\hline 3 June 2006 & $04: 13$ & $04: 15$ & 87 & 0.31 & 0.02 & 0.011 & 0.27 & 0.32 & 0.060 & 0.013 & \\
\hline 4 June 2006 & 09:41 & $09: 52$ & 87 & 0.34 & 0.02 & 0.011 & 0.32 & 0.37 & 0.166 & 0.004 & AOD 0.481 \\
\hline 5 June 2006 & $21: 13$ & $21: 26$ & 87 & 0.3 & 0.03 & 0.029 & 0.21 & 0.32 & 0.163 & 0.011 & \\
\hline 6 June 2006 & $10: 10$ & $10: 30$ & 87 & 0.31 & 0.03 & 0.006 & 0.29 & 0.33 & 0.185 & 0.010 & AOD 0.52 \\
\hline \multicolumn{12}{|c|}{ DLR-HSRL (532 nm) } \\
\hline 19 May 2006 & $11: 06$ & $11: 12$ & & 0.30 & 0.03 & 0.007 & 0.29 & 0.31 & & & \\
\hline 20 May 2006 & $11: 00$ & $11: 03$ & & 0.31 & 0.03 & 0.005 & 0.30 & 0.33 & & & \\
\hline 28 May 2006 & $10: 42$ & $10: 43$ & & 0.32 & 0.03 & 0.004 & 0.30 & 0.32 & & & \\
\hline 3 June 2006 & $04: 13$ & $04: 15$ & & 0.31 & 0.03 & 0.006 & 0.30 & 0.32 & & & \\
\hline 4 June 2006 & $09: 46$ & 09:48 & & 0.30 & 0.03 & 0.007 & 0.29 & 0.31 & & & \\
\hline \multicolumn{12}{|c|}{ DLR-HSRL (1064 nm) } \\
\hline 19 May 2006 & 11:06 & $11: 12$ & & 0.27 & 0.04 & 0.005 & 0.26 & 0.28 & & & \\
\hline 20 May 2006 & 11:00 & 11:03 & & 0.28 & 0.04 & 0.004 & 0.26 & 0.29 & & & \\
\hline 3 June 2006 & $04: 13$ & $04: 15$ & & 0.26 & 0.04 & 0.007 & 0.22 & 0.27 & & & \\
\hline \multicolumn{12}{|l|}{ POLIS (355 nm) } \\
\hline 19 May 2006 & $10: 59$ & $11: 19$ & & 0.24 & 0.07 & 0.009 & 0.22 & 0.26 & & & \\
\hline 3 June 2006 & $04: 12$ & $04: 16$ & & 0.28 & 0.05 & 0.021 & 0.21 & 0.31 & & & \\
\hline \multicolumn{12}{|c|}{ BERTHA $(710 \mathrm{~nm})$} \\
\hline 03 June 2006 & 04:00 & 05:00 & 90 & 0.26 & 0.04 & 0.009 & 0.23 & 0.28 & & & \\
\hline 4 June 2006 & $09: 24$ & $10: 29$ & 90 & 0.30 & 0.05 & 0.010 & 0.28 & 0.33 & & & \\
\hline
\end{tabular}

Note: Elev. denotes the lidar angle from horizontal. Ångström exponents (440-870 nm) and AOD (500 nm) are from temporally closest SSARA measurements. Height ranges in the comment are given on 30 June for the two distinguished dust layers.

2000; Sakai et al., 2002; Shimizu et al., 2004; Sugimoto et al., 2002; Ansmann et al., 2003; Murayama et al., 2004; Müller et al., 2003; Chen et al., 2007). As a consequence, the linear particle depolarization ratio $\delta^{\mathrm{p}}$ is typically found to be 0.10 to
0.25 and thus, considerably lower than the value for pure dust as presented above. Several measurements in young and most probably pure or almost pure dust plumes, performed close to the Sahara (Gobbi et al., 2000) and close to the Taklamakan desert 


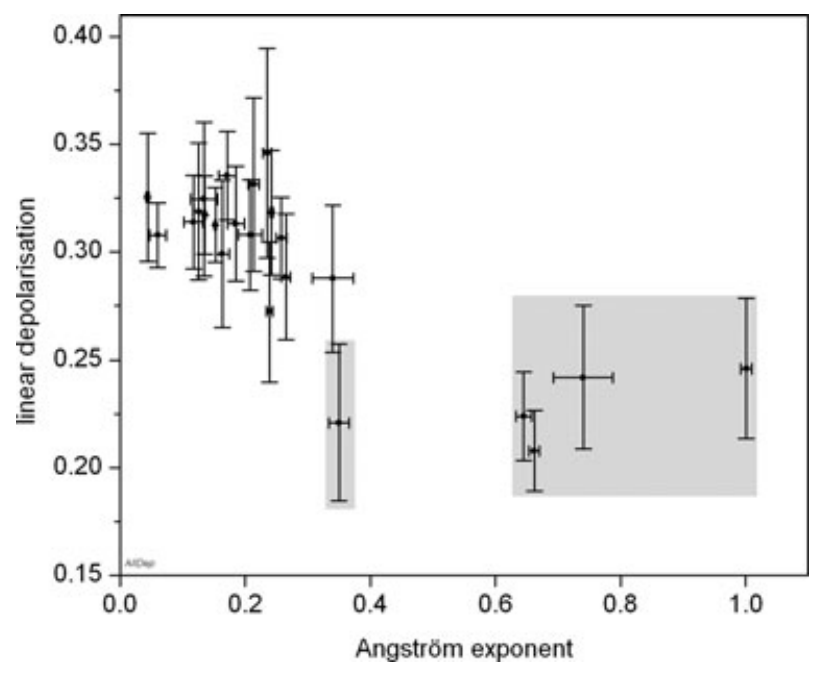

Fig. 9. Columnar linear particle depolarization ratio in the dust layer from MULIS at $532 \mathrm{~nm}$ over SSARA Ångström exponent $(440-870 \mathrm{~nm})$. The vertical error bars indicate the systematic uncertainty of the mean, whereas the horizontal error bars show the standard deviation of the AE during the lidar averaging periode or the uncertainty due to the interpolation of the SSARA values during night and cloudy periods.

(Iwasaka et al., 2003) or in well-isolated Gobi dust layers in the free troposphere above Japan (Sakai et al., 2000; Murayama et al., 2004) indicate that the maximum linear volume (molecular plus particle) depolarization ratio $\delta^{v}$ in desert dust layers is close to 0.3 and the maximum particle depolarization ratio $\delta^{\mathrm{p}}$ is close to $0.3-0.35$ at $532 \mathrm{~nm}$. Focusing on Saharan dust, Gobbi et al. (2000) show for backscatter ratios $\mathbf{R}$ of 4 and more linear volume depolarization ratios $\delta^{v}$ of 0.3 during a campaign on Crete, Greece, about $500 \mathrm{~km}$ north of Africa. Our results are in full agreement with these studies.

\section{Summary}

We report measurements of the linear particle depolarization ratios $\delta^{\mathrm{p}}$ of pure Saharan dust with four lidar systems at four wavelengths in Quarzazate, Morocco, during SAMUM in May-June 2006. We evaluate the errors and their sources of the calibration methods used for the different lidars, and achieve trustworthy error estimations for the linear depolarization ratios. The confidence in the procedures is confirmed by the agreement of the $\delta^{\mathrm{p}}$ values of MULIS and DLR-HSRL within the error bars at $532 \mathrm{~nm}$. It turns out that the main error source is not the signal noise, as it can, in general, be reduced sufficiently by means of spatial or temporal averaging. The uncertainty of $\delta^{\mathrm{p}}$ comes primarily, at least in our data set, from systematic errors in the setup of the lidar systems, which cannot be reduced by statistical methods. We found the main error sources to originate from the depolarization calibration $\left(\boldsymbol{V}^{*}\right)$, with large differences between the different calibration methods, and from the error of the particle backscatter coefficient $\beta^{\mathrm{p}}$ (or backscatter ratio $\mathbf{R}$ ) due to the uncertainty in the height-dependent lidar ratio $S(r)$ and the uncertainty in the signal calibration in the assumed clean, free troposphere $\beta^{\mathrm{p}}\left(r_{0}\right)$. Using the derived error formulas and estimations of the basic errors, the $\delta^{\mathrm{p}}$ values have a mean relative uncertainty at $532 \mathrm{~nm}$ of $\pm 10 \%$ (MULIS and DLR-HSRL), $\pm 15 \%$ at $1064 \mathrm{~nm}, \pm 16 \%$ at $710 \mathrm{~nm}$ and $\pm 25 \%$ at $355 \mathrm{~nm}$. The linear particle depolarization ratio $\delta^{\mathrm{p}}$ of MULIS at $532 \mathrm{~nm}$ are determined as means over the boundary/dust layer on 24 dates, and as a mean of these data over the 19 pure dust cases we find a mean $\delta^{\mathrm{p}}$ of 0.31 at $532 \mathrm{~nm}$, with a standard deviation of 0.02 and $\min . /$ max. values of $0.27 / 0.35$, respectively. The comparison of the whole $\delta^{\mathrm{p}}$ data set $(532 \mathrm{~nm})$ with the corresponding AEs (440-870 nm) from the sunphotometer SSARA exhibits a negative correlation, with AEs between 0.04 and 0.34 for the pure dust cases and between 0.65 and 1.00 for the intermediate periods. Three coincident measurements of MULIS (532 nm) and the air borne DLR-HSRL (532 and $1064 \mathrm{~nm}$ ) show a weak wavelength dependence of the $\delta^{\mathrm{p}}$ of pure dust with a decrease from $0.31 \pm 0.03$ at $532 \mathrm{~nm}$ to $0.27 \pm 0.04$ at $1064 \mathrm{~nm}$.

\section{Acknowledgments}

We are grateful to the Moroccan Ministry for Foreign Affairs and the Ministry of the Interior for the permission to carry out the SAMUM field campaign in Morocco. We would like to extend our gratefulness to the Moroccan Airport Authority and, in particular, to respectable Monsieur Mohammed El Mardi, commander of Ouarzazate airport, for their extraordinary and unbureaucratic support of the participants of SAMUM. We would also

Table 3. Summary of columnar linear particle depolarization ratios from MULIS $532 \mathrm{~nm}$ measurements in the dust layers and Ångström exponents for $440-870 \mathrm{~nm}$ from SSARA for different air masses/time periods

\begin{tabular}{lcccccrr}
\hline Date & $\begin{array}{c}\text { Depol. } \\
\text { mean }\end{array}$ & $\begin{array}{c}\text { Depol. } \\
\text { range }\end{array}$ & $\begin{array}{c}\text { Depol. } \\
\text { mean } S D\end{array}$ & $\begin{array}{c}\text { Ånström } \\
440-870 \mathrm{~nm}\end{array}$ & $\begin{array}{c}\text { Angström } \\
\text { exponent range }\end{array}$ & $\begin{array}{c}\text { Angström } \\
\text { exponent } S D\end{array}$ & $\begin{array}{c}\text { Airmass } \\
\text { Intermediate }\end{array}$ \\
\hline 23 May (20 UT) & 0.22 & & & 0.35 & & 0.16 & Intermediate \\
29 May (21 UT) to 1 June (12 UT) & 0.23 & $0.21-0.25$ & 0.02 & 0.76 & $0.65-1.00$ & 0.08 & Dust \\
Other days & 0.31 & $0.27-0.35$ & 0.02 & 0.18 & $0.04-0.34$ & 0.08 \\
\hline
\end{tabular}


like to thank Nabil Bousselham for his dedicated support of the research teams. The SAMUM research group is funded by the Deutsche Forschungsgemeinschaft (DFG) under grant number FOR 539. We further thank the Johannes Gutenberg University Mainz for its financial support through the research funds of the University of Mainz.

\section{Appendix A: Error analysis}

Statistical noise errors from photon statistics and amplification noise are not considered here. It can be reduced by means of averaging over time and hight and is small compared with the systematic errors. The particle depolarization ratio $\delta^{\mathrm{p}}$ of all lidar systems is calculated by means of eq. (20), from the constant but system-dependent linear molecular depolarization ratio $\delta^{\mathrm{m}}$, the height-dependent linear volume depolarization ratio $\delta^{\mathrm{v}}$ and the backscatter ratio $\mathbf{R}$.

\section{A.1. MULIS}

Reformulation of eq. (20) for MULIS gives

$\delta^{\mathrm{p}}=\frac{\delta^{\mathrm{v}}\left(1+\delta^{\mathrm{m}}\right) B+\left(\delta^{\mathrm{v}}-\delta^{\mathrm{m}}\right)}{\left(1+\delta^{\mathrm{m}}\right) B-\left(\delta^{\mathrm{v}}-\delta^{\mathrm{m}}\right)}$,

with

$B=\boldsymbol{R}-1=\frac{\beta^{\mathrm{p}}}{\beta^{\mathrm{m}}}$.

With the assumptions

$\delta^{\mathrm{m}}=0.0036 \ll 1, \quad$ and $\quad \delta^{\mathrm{m}} \ll \delta^{\mathrm{v}}$

in dust layers, it follows

$\delta^{\mathrm{p}} \approx \delta^{\mathrm{v}} \frac{B+1}{B-\delta^{\mathrm{v}}}=\frac{B+1}{\frac{B}{\delta^{\mathrm{v}}}-1}$.

The uncertain lidar system parameters, which cause the systematic error, do not change during the measurement, and thus the error in the linear particle depolarization ratio must be derived from

$\Delta \delta^{\mathrm{p}}=\left|\frac{\mathrm{d} \delta^{\mathrm{p}}}{\mathrm{d} B} \Delta B\right|+\left|\frac{\mathrm{d} \delta^{\mathrm{p}}}{\mathrm{d} \delta^{\mathrm{v}}} \Delta \delta^{\mathrm{v}}\right|$.

With eq. (A.4), follows

$\frac{\Delta \delta^{\mathrm{p}}}{\delta^{\mathrm{p}}} \approx\left|\frac{B}{B-\delta^{\mathrm{v}}}\right| \times\left(\left|\frac{\delta^{\mathrm{v}}+1}{B+1} \frac{\Delta B}{B}\right|+\left|\frac{\Delta \delta^{\mathrm{v}}}{\delta^{\mathrm{v}}}\right|\right)$.

The relative error of $B$ is calculated from eq. (A.2) with

$\frac{\Delta B}{B}=\frac{\Delta \beta^{\mathrm{p}}}{\beta^{\mathrm{p}}}+\frac{\Delta \beta^{\mathrm{m}}}{\beta^{\mathrm{m}}}=\frac{\Delta \beta^{\mathrm{p}}}{\beta^{\mathrm{p}}}$.

The particle backscatter coefficient $\beta^{\mathrm{p}}$ is derived from the total signal using Klett's inversion, for which a reference value $\beta^{\mathrm{p}}\left(r_{0}\right)$ at a reference range $r_{0}$ is needed, and the range-dependent lidar ratios $S(r)$. We determined the range-dependent error of $\beta^{\mathrm{p}}$ from the maximum difference we can get when using minimum and maximum values of $\beta^{\mathrm{p}}\left(r_{0}\right)$ and $S(r)$. The error in $\beta^{\mathrm{p}}\left(r_{0}\right)$ was estimated considering the signal noise around range $r_{0}$ and the systematic signal distortions in the free troposphere as explained in chapter 3.1. For coincident measurements with the DLRHSRL, the $S(r)$ and their errors $( \pm 5 \mathrm{sr})$ were adopted from the analysis of the DLR-HSRL signals. For other measurements, we used a constant lidar ratio of $50 \mathrm{sr}$ with an error of $\pm 10 \mathrm{sr}$. The linear volume depolarization ratio $\delta^{\mathrm{v}}$ was measured with MULIS at $\varphi=90^{\circ}$ (eq. 16), and thus, we derive the error from

$\Delta \delta^{\mathrm{v}}=\left|\frac{\mathrm{d} \delta^{\mathrm{v}}}{\mathrm{d} V^{*}} \Delta V^{*}\right|+\left|\frac{\mathrm{d} \delta^{\mathrm{v}}}{\mathrm{d} \delta^{*}} \Delta \delta^{*}\right|+\left|\frac{\mathrm{d} \delta^{\mathrm{v}}}{\mathrm{d} R_{\mathrm{s}}} \Delta R_{\mathrm{s}}\right|$

and

$\delta^{\mathrm{v}}=\frac{\frac{V^{*}}{\delta^{*}} R_{\mathrm{s}}-T_{\mathrm{s}}}{T_{\mathrm{p}}-\frac{V^{*}}{\delta^{*}} R_{\mathrm{p}}} \approx \frac{V^{*}}{\delta^{*}} R_{\mathrm{s}}-T_{\mathrm{s}}=\left(\frac{V^{*}}{\delta^{*}}+1\right) R_{\mathrm{s}}-1$,

considering only major contributions. With $V^{*} / \delta^{*} \approx \delta^{v}$, we get

$\frac{\Delta \delta^{\mathrm{v}}}{\delta^{\mathrm{v}}} \approx\left|\frac{\Delta V^{*}}{V^{*}}\right|+\left|\frac{\Delta \delta^{*}}{\delta^{*}}\right|+\left|\frac{\Delta R_{\mathrm{s}}}{R_{\mathrm{s}}}\right|+\left|\frac{\Delta R_{\mathrm{s}}}{\delta^{\mathrm{v}}}\right|$.

Neglecting $\Delta R_{\mathrm{S}} / R_{\mathrm{s}}$ and the signal noise $\Delta \delta^{*} / \delta^{*}$, we arrive at

$\frac{\Delta \delta^{v}}{\delta^{v}} \approx\left|\frac{\Delta V^{*}}{V^{*}}\right|+\left|\frac{\Delta R_{\mathrm{s}}}{\delta^{\mathrm{v}}}\right|$.

Due to the divergence of the incident beam on the PBC of about $\pm 2^{\circ}$, the effective value of $R_{\mathrm{S}}$ is estimated to be $0.9965 \pm 0.002$, whereas no change and error of $T_{\mathrm{p}}$ is assumed. Calibration constants $V^{*}$ determined on different days for the same lidar setup show relative differences lower than $1 \%$, and thus, we conservatively estimate the relative error $\left|\Delta V^{*} / V^{*}\right|=$ 0.01 . As a future refinement, the error in $\delta^{\mathrm{m}}$ caused by the retrieval from radiosonde data could be investigated, as well as the error due to the bandwidth of the interference filter (see below, DLR-HSRL).

\section{A.2. BERTHA}

The error analysis of BERTHA follows that of MULIS above with an additional term for the diattenuation $\mathrm{D}$ of the optical elements before the PBC (eq. 27) with $|\Delta D / D|=0.02$. Errors of $R_{\mathrm{S}}$ and $T_{\mathrm{p}}$ are neglected, and hence eq. (A.11) reads

$\frac{\Delta \delta^{v}}{\delta^{v}} \approx\left|\frac{\Delta V^{*}}{V^{*}}\right|+\left|\frac{\Delta D}{D}\right|$

The relative error of the particle backscatter coefficient is estimated to be $\left|\Delta \beta^{\mathrm{p}} / \beta^{\mathrm{p}}\right|=0.1$, and the use of the $45^{\circ}$-calibration with a polarizing sheet filter results in $\left|\Delta V^{*} / V^{*}\right|=0.12$. The latter is retrieved from the maximum deviation of several calibration measurements performed during SAMUM. 


\section{A.3. POLIS}

The approach for POLIS is the same as for MULIS above (eqs. A.1-A.5) but without the assumption $\delta^{\mathrm{m}} \ll \delta^{\mathrm{v}}$, which results in a more general formula for the relative error of $\delta^{\mathrm{p}}$ at $355 \mathrm{~nm}$

$$
\begin{aligned}
\frac{\Delta \delta^{\mathrm{p}}}{\delta^{\mathrm{p}}}= & \left|\frac{B^{*}\left(\delta^{\mathrm{v}}+1\right)\left(\delta^{\mathrm{m}}-\delta^{\mathrm{v}}\right)}{K\left(\delta^{\mathrm{v}}+1-K\right)} \frac{\Delta B^{*}}{B^{*}}\right| \\
& +\left|\frac{\delta^{\mathrm{v}}\left(B^{*}+1\right)}{K\left(\delta^{\mathrm{v}}+1-K\right)} \frac{\Delta \delta^{\mathrm{v}}}{\delta^{\mathrm{v}}}\right|,
\end{aligned}
$$

with the substitutions (please note the difference from eq. A.2)

$$
\begin{aligned}
B^{*} & =\frac{\beta^{\mathrm{m}}}{\beta^{\mathrm{p}}}, \\
K & =\left[B^{*}\left(\delta^{\mathrm{m}}-\delta^{\mathrm{v}}\right)+1\right] .
\end{aligned}
$$

The accuracy of $\pm 1^{\circ}$ in the $90^{\circ}$ difference for the $\pm 45^{\circ}$ calibration method is not accurate enough, and thus, the error of the $45^{\circ}$-calibration in dust must be applied (see Fig. 2), resulting in $\left|\Delta V^{*} / V^{*}\right|=0.035$. Due to saturation of the photon counting signals, only the analog signals were used. Distortions of the analog signals during the $\pm 45^{\circ}$-calibration due to high nearrange signal from the dust layer caused the largest error of $V^{*}$ during SAMUM. A constant lidar ratio of $55 \mathrm{sr}$ is used for the Fernald inversion, and the error of $\beta^{\mathrm{p}}$ is derived by applying lidar ratios of 45 and $65 \mathrm{sr}$. The influence of different reference values $\beta^{\mathrm{p}}\left(r_{0}\right)$ between 0.05 and $0.2 \mathrm{Mm}^{-1} \mathrm{~s} \mathrm{r}^{-1}$ for initializing the inversion algorithm, chosen for $\boldsymbol{r}_{\mathbf{0}}$ just above the dust layer, is small compared with the effects due to lidar ratio changes.

\section{A.3. DLR-HSRL}

The error analysis here is different, because the DLR-HSRL is different from the other three lidars in two aspects: first, it looks downwards from the airplane flying above the dust layer, which results in a strong signal from the free troposphere where the signal calibration with respect to the molecular backscatter $\beta^{\mathrm{m}}$ can be done, and secondly, it measures the aerosol (particle) transmission $\tau^{\mathrm{p}^{2}}(r)$ rather directly with the high spectral resolution channel (HSR), quite fast, with high accuracy and also in daylight (Esselborn et al., 2008). Therefore, the backscatter ratio $\mathbf{R}$ can be retrieved directly from the measured signals from

$\mathbf{R}(r)=\frac{\mathbf{R}_{T}(r)}{\tau^{\mathrm{p}^{2}}(r)}$,

and eq. (20) reformulated to

$\delta^{\mathrm{p}}=\frac{\beta_{\perp}^{\mathrm{p}}}{\beta_{\|}^{\mathrm{p}}}=\frac{\left(1+\delta^{\mathrm{m}}\right) \delta^{\mathrm{v}} \frac{\mathbf{R}_{T}}{\tau^{\mathrm{p}^{2}}}-\left(1+\delta^{\mathrm{v}}\right) \delta^{\mathrm{m}}}{\left(1+\delta^{\mathrm{m}}\right) \frac{\mathbf{R}_{T}}{\tau^{\mathrm{p}^{2}}}-\left(1+\delta^{\mathrm{v}}\right)}$,

where $\tau^{\mathrm{p}^{2}}(r)$ denotes the aerosol transmission over range $r$ from the lidar transmitter to the scattering volume and back and $\mathbf{R}_{\mathbf{T}}(r)$ is the total (parallel- and cross-polarized) attenuated backscatter ratio resulting from calibrating the lidar signals to molecular backscatter $\beta^{\mathrm{m}}$ in a region in the free troposphere, where aerosol backscatter can be neglected. Although this procedure is considered rather unreliable for ground based lidars with week signals in the calibration range, it is much more reliable for an airborne lidar flying in the free troposphere. However, the uncertainty $\Delta \mathbf{R}$ is mainly due to the calibration because the amount of background aerosol at the reference altitude is unknown a priori and has to be estimated. In addition, the error of $\mathbf{R}$ in the calibration range has a relatively strong influence on the retrieval of all other parameters. If available, the value of background aerosol backscatter was estimated from in situ measurements performed aboard the Falcon at the reference altitude (Esselborn et al., 2008; Weinzierl et al., 2008). The systematic error of $\delta^{\mathrm{p}}$ is calculated from

$\Delta \delta^{\mathrm{p}}=\left|\frac{\partial \delta^{\mathrm{p}}}{\partial \mathbf{R}} \Delta \mathbf{R}\right|+\left|\frac{\partial \delta^{\mathrm{p}}}{\partial \delta^{\mathrm{v}}} \Delta \delta^{\mathrm{v}}\right|+\left|\frac{\partial \delta^{\mathrm{p}}}{\partial \delta^{\mathrm{m}}} \Delta \delta^{\mathrm{m}}\right|$.

The relative error of $\mathrm{R}$ is determined from eq. (A.15)

$$
\frac{\Delta \mathbf{R}}{\mathbf{R}}=\frac{\Delta \mathbf{R}_{T}}{\mathbf{R}_{T}}+\frac{\Delta \tau^{p^{2}}}{\tau^{p^{2}}} .
$$

The value of $\delta^{\mathrm{m}}$ critically depends on the amount of detected rotational Raman scattering (Behrendt and Nakamura, 2002). The partial transmission of pure rotational Raman scattering through the background filters is calculated and results in a value of $\delta^{\mathrm{m}}=6.8 \times 10^{-3}$. The uncertainty $\Delta \delta^{\mathrm{m}}$ is estimated as the difference of the theoretic maximum value of $1.4 \times 10^{-2}$ (full inclusion of rotational Raman scattering) and the calculated value of $6.8 \times 10^{-3} \cdot \delta^{\mathrm{v}}$ is evaluated from eq. (24). In case of the $532 \mathrm{~nm}$ branch, the subscript $C$ differentiates the combined from the molecular (HSRL) channel. To determine $V^{*}$ a $45^{\circ}$-calibration must be performed during the flight. The whole receiver module is manually rotated to the $45^{\circ}$ position with respect to the laser polarization, and $V^{*}$ can be derived for each wavelength. The mechanical precision and the reproducibility of the initial adjustment is estimated to have a tolerance of $\pm 0.6^{\circ}$. Thus, the determination of $V^{*}$ has a relative error of $4.5 \%$ (cf. Fig. 2), contributing the largest systematic error. In case of the $1064 \mathrm{~nm}$ branch, $\tau^{\mathrm{p} 2}(r)$ is calculated from the directly measured aerosol optical thickness profile at $532 \mathrm{~nm}$, and the 500 1020-nm AE from local AERONET measurements. The partial derivatives of eq. (A.17) can be written as

$$
\begin{aligned}
\frac{\partial \delta^{\mathrm{p}}}{\partial \mathbf{R}} & =\frac{\delta^{\mathrm{m}}\left(1+\delta^{\mathrm{m}}+\delta^{\mathrm{m}} \delta^{\mathrm{v}}\right)-\delta^{\mathrm{v}}\left(1+\delta^{\mathrm{v}}+\delta^{\mathrm{m}} \delta^{\mathrm{v}}\right)}{\left(\mathbf{R}+\mathbf{R} \delta^{\mathrm{m}}-\delta^{\mathrm{v}}-1\right)^{2}}, \\
\frac{\partial \delta^{\mathrm{p}}}{\partial \delta^{\mathrm{v}}} & =\frac{\mathbf{R}^{2}-\mathbf{R}+\mathbf{R} \delta^{\mathrm{m}}\left(2 \mathbf{R}+\mathbf{R} \delta^{\mathrm{m}}-\delta^{\mathrm{m}}-2\right)}{\left(\mathbf{R}+\mathbf{R} \delta^{\mathrm{m}}-\delta^{\mathrm{v}}-1\right)^{2}}, \\
\frac{\partial \delta^{\mathrm{p}}}{\partial \delta^{\mathrm{m}}} & =\frac{\delta^{\mathrm{v}}\left(1+\mathbf{R} \delta^{\mathrm{v}}-2 \mathbf{R}\right)+1-\mathbf{R}}{\left(\mathbf{R}+\mathbf{R} \delta^{\mathrm{m}}-\delta^{\mathrm{v}}-1\right)^{2}} .
\end{aligned}
$$

\section{References}

Althausen, D., Müller, D., Ansmann, A., Wandinger, U., Hube, H. and co-authors. 2000. Scanning 6-wavelength 11-channel aerosol lidar. J. Atmos. Ocean. Technol. 17, 1469-1482. 
Alvarez, J. M., Vaughan, M. A., Hostetler, C. A., Hunt, W. H. and Winker, D. M. 2006. Calibration technique for polarization-sensitive lidars. J. Atmos. Ocean. Technol. 23, 683-699.

Ansmann, A., Bösenberg, J., Chaikovsky, A., Comerón, A., Eckhardt, S. and co-authors. 2003. Long-range transport of Saharan dust to northern Europe: the 11-16 October 2001 outbreak observed with EARLINET. J. Geophys. Res. 108, doi:10.1029/2003JD003757.

Ansmann, A., Mattis, I., Müller, D., Wandinger, U., Radlach, M. and co-authors. 2005. Ice formation in Saharan dust over central Europe observed with temperature/humidity/aerosol Raman lidar. J. Geophys. Res. 110, doi:10.1029/2005JD005000.

Ansmann, A., Tesche, M., Althausen, D., Müller, D., Freudenthaler, V. and co-authors. 2007. Influence of Saharan dust on cloud glaciation in southern Morocco during SAMUM. J. Geophys. Res. 112, doi:10.1029/2007JD008575.

Behrendt, A. and Nakamura, T. 2002. Calculation of the calibration constant of polarization lidar and its dependency on atmospheric temperature. Optics Exp. 10, 805-817.

Biele, J., Beyerle, G. and Baumgarten G. 2000. Polarization lidar: corrections of instrumental effects. Optics Exp. 7, 427-435.

Cairo, F., Di Donfrancesco, G., Adriani, A., Lucio, P. and Federico, F. 1999. Comparison of various linear depolarization parameters measured by lidar. Appl. Opt. 38, 4425-4432.

Chen, W. N., Tsai, F. J., Chou, C. C. K., Chang, S. Y., Chen, Y. W. and coauthors. 2007. Optical properties of Asian dust in the free atmosphere measured by raman lidar at Taipei, Taiwan. Atmos. Environ. 41, 76987714.

Dubovik, O., Sinyuk, A., Lapyonok, T., Holben, B. N., Mishchenko, M. and co-authors. 2006. Application of spheroid models to account for aerosol particle nonsphericity in remote sensing of desert dust. J. Geophys. Res. 111, doi:10.1029/2005JD006619.

Esselborn, M., Wirth, M. Fix, A., Tesche, M. and Ehret, G. 2008. Airborne high spectral resolution lidar for measuring aerosol extinction and backscatter coefficients. Appl. Opt. 47, 346358.

Esselborn, M., Wirth, M., Fix, A., Weinzierl, B., Rasp, K. and co-authors. 2008. Spatial distribution and optical properties of Saharan dust observed by airborne high spectral resolution lidar during SAMUM 2006. Tellus 61B, doi:10.1111/j.1600-0889.2008.00394.x.

Fernald, F. G. 1984. Analysis of atmospheric lidar observations: some comments. Appl. Opt. 23, 652-653.

Freudenthaler, V., Homburg, F. and Jäger, H. 1996. Optical parameters of contrails from lidar measurements: linear depolarization. Geophys. Res. Lett. 23, 3715-3718.

Gobbi, G. P., 1998. Polarization lidar returns from aerosols and thin clouds: a framework for the analysis. Appl. Opt. 37, 55055508.

Gobbi, G. P., Barnaba, F., Giorgi, R. and Santacasa, A. 2000. Altituderesolved properties of a Saharan dust event over the Mediterranean. Atmos. Environ. 34, 5119-5127.

Hayashida, S., Kobayashi, A. and Iswasaka, Y. 1984. Lidar measurements of stratospheric aerosol content and depolarization ratios after the eruption of El Chichon volcano: measurements at Nagoya, Japan. Geofis. Int. 23, 277-288.

Heese, B., Freudenthaler, V., Seefeldner, M. and Wiegner, M. 2002. POLIS: a new portable system for ground-based and airborne measurements of aerosols and clouds. In: Lidar Remote Sensing in At- mospheric and Earth Sciences (eds. L. R. Bissonnette, G. Roy and G. Vallee). Defence Research and Development, Canada-Valcartier, Val-Belair, QU, Canada , 71-74.

Iwasaka, Y., Shibata, T., Nagatani, T., Shi, G.-Y., Kim, Y. S. and coauthors. 2003. Large depolarization ratio of free tropospheric aerosols over the Taklamakan desert revealed by lidar measurements: possible diffusion and transport of dust particles. J. Geophys. Res. 108, doi:10.1029/2002JD003267.

Kandler, K., Schütz, L., Deutscher, C., Ebert, M., Hofmann, H. and co-authors. 2008. Size distribution, mass concentration, chemical and mineralogical composition and derived optical parameters of the boundary layer aerosol at Tinfou, Morocco, during SAMUM 2006. Tellus 61B, doi:10.1111/j.1600-0889.2008.00385.x.

Klett, J. D. 1985. Lidar Inversion with Variable Backscatter/Extinction Ratios. Appl.Opt. 24, 1638-1643.

Knippertz, P., Ansmann, A., Althausen, D., Tesche, M., Bierwirth, E. and co-authors. 2008. Dust mobilization and transport in the northern Sahara during SAMUM 2006-a meteorological overview. Tellus 61B, doi:10.1111/j.1600-0889.2008.00380.x.

McNeil, W. R. and Carswell, A. I. 1975. Lidar polarization studies of the troposphere. Appl. Opt. 14, 2158-2168.

Mishchenko, M. I. and Sassen, K. 1998. Depolarization of lidar returns by small ice crystals: an application to contrails. Geophys. Res. Lett. 25, 309-312.

Müller, D., Mattis, I., Wandinger, U., Ansmann, A., Althausen, D. and co-authors. 2003. Saharan dust over a central European EARLINETAERONET site: combined observations with Raman lidar and Sun photometer. J. Geophys. Res. 108, doi:10.1029/2002JD002918.

Murayama, T., Furushima, M., Oda, A. and Iwasaka, N. 1996. Depolarization ratio measurements in the atmospheric boundary layer by lidar in Tokyo. J. Meteorol. Soc. Japan 74, 571-578.

Murayama, T., Masonis, S. J., Redemann, J., Anderson, T. L., Schmid, B. and co-authors. 2003. An intercomparison of lidar-derived aerosol optical properties with airborne measurements near Tokyo during ACE-Asia. J. Geophys. Res. 108, doi:10.1029/2002JD003259.

Murayama, T., Müller, D., Wada, K., Shimizu, A., Sekiguchi, M. and co-authors. 2004. Characterization of Asian dust and Siberian smoke with multiwavelength Raman lidar over Tokyo, Japan in spring 2003. Geophys. Res. Lett. 31, doi:10.1029/2004GL021105.

Reichardt, J., Tsias, A. and Behrendt, A. 2000. Optical properties of PSC Ia-enhanced at UV and visible wavelengths: model and observations. Geophys. Res. Lett. 27, 201-204.

Reichardt, J., Baumgart, R. and McGee, T. J. 2003. Three-signal method for accurate measurements of depolarization ratio with lidar. Appl. Opt. 42, 4909-4913.

Sakai, T., Shibata, T., Kwon, S.-A., Kim, Y.-S., Tamura, K. and coauthors. 2000. Free tropospheric aerosol backscatter, depolarization ratio, and relative humidity measured with the Raman lidar at Nagoya in 1994-1997: contribution of aerosols from the Asian contient and the Pacific Ocean. Atmos. Environ. 34, 431-442.

Sakai, T., Shibata, T., Iwasaka, Y., Nagai, T., Nakazato, M. and coauthors. 2002. Case study of Raman lidar measurements of Asian dust events in 2000 and 2001 at Nagoya and Tsukuba, Japan. Atmos. Environ. 36, 5479-5489.

di Sarra, A., Di Iorio, T., Cacciani, M., Fiocco, G. and Fuà, D. 2001. Saharan dust profiles measured by lidar at Lampedusa. J. Geophys. Res. 106, 10335-10347. 
Sassen, K. 1991. The polarization lidar technique for cloud research: a reviwe and current assessments. Bull. Am. Meteorol. Soc. 72, 18481866.

Sassen, K. 2005. Polarization in lidar. In: Lidar (ed. C. Weitkamp). Springer, New York, 19-42.

Sassen, K., Zhu, J., Webley, P., Dean, K. and Cobb, P. 2007. Volcanic ash plume identification using polarization lidar: Augustine eruption, Alaska. Geophys. Res. Lett. 34, doi:10.1029/2006GL027237.

Schotland, R. M., Sassen, K. and Stone, R. 1971. Observations by lidar of linear depolarization ratios for hydrometeors. J. Appl. Meteorol. 10, 1011-1017.

Shimizu, A., Sugimoto, N., Matsui, I., Arao, K., Uno, I. and co-authors. 2004. Continuous observations of Asian dust and other aerosols by polarization lidar in China and Japan during ACE-Asia. J. Geophys. Res. 109, D19S17, doi:10.1029/2002JD003253.

Sugimoto, N., Matsui, I., Shimizu, A., Uno, I., Asai, K. and coauthors. 2002. Observation of dust and anthropogenic aerosol plumes in the Northwest Pacific with a two-wavelength polarization lidar on board the research vessel Mirai. Geophys. Res. Lett. 29, doi:10.1029/2002GL015112.

Tesche, M., Ausmann, A., Müller, D., Althausen, D., Mattis, I. and co- authors. 2008. Vertical profiling of Saharan dust with Raman Lidars and airborne HSRL in southern Morocco during SAMUM. Tellus 61B, doi:10.1111/j.1600-0889.2008.00390.x.

Toledano, C., Wiegner, M., Garhammer, M., Seefeldner, M., Freudenthaler, V. and co-authors. 2008. Spectral aerosol optical depth characterization of desert dust during SAMUM 2006. Tellus 61B, doi:10.1111/j.1600-0889.2008.00382.x.

Toon, O., Tabazadeh, A., Browell, E. and Jordan, J. 2000. Analysis of lidar observations of Arctic polar stratospheric clouds during January 1989. J. Geophys. Res. 105, 20 589-20 615.

Weinzierl, B., Pretzold, M., Esselborn, M., Wirth, K., Rasp, K. and co-authors. 2008. Airborne measurements of dust layer properties, particle size distribution and mixing state of Saharan dust during SAMUM 2006. Tellus 61B, doi:10.1111/j.1600-0889.2008.00392.x.

Wiegner, M., Gasteiger, J., Kandler, K., Weinzierl, B., Rasp, K. and coauthors. 2008. Numerical simulations of optical properties of Saharan dust aerosols with special emphasis on the linear depolarization ratio. Tellus 61B, doi:10.1111/j.1600-0889.2008.00381.x.

Winker, D. and Osborn, M. 1992. Preliminary analysis of observations of the Pinatubo volcanic plume with a polarization-sensitive lidar. Geophys. Res. Lett. 19, 161-174. 